\title{
PRIMEROS RESULTADOS DE LAS INVESTIGACIONES ARQUEOLÓGICAS EN EL DELTA SUPERIOR DEL PARANÁ Y SU CONTRIBUCIÓN AL ATLAS ARQUEOLÓGICO DE LA PROVINCIA DE ENTRE RÍOS
}

\author{
First Results of Archaeological Research in the Upper Delta of Parana River and its \\ Contribution to the Archaeological Atlas of the Province of Entre Rios
}

Mariano Bonomo, Gustavo Politis y Juan Carlos Castro

\section{Resumen}

En este trabajo se dan a conocer los resultados de las prospecciones intensivas y sondeos estratigráficos llevados a cabo en el Delta Superior del río Paraná. Los sitios registrados $(n=52)$ confirman el alto potencial arqueológico del área y se integran con la base de datos que conforman el atlas arqueológico de la provincia de Entre Ríos. Se resume la información obtenida en recolecciones superficiales y en los sondeos y se dan a conocer las primeras dataciones radiocarbónicas generadas en el marco del proyecto. Se articulan los sitios relevados en el Delta Superior con las unidades geomorfológicas propuestas por Cavallotto et al. (2005) y se discuten brevemente las tendencias de ocupación indígena del área de estudio en relación al espacio disponible durante el Holoceno tardío. Por último, se relacionan los sitios elevados ("cerritos") con contextos similares en las Tierras Bajas de América del Sur.

$<$ Delta del río Paraná $><$ Holoceno tardío $><$ Prospecciones intensivas $><$ "Cerritos" $>$

\begin{abstract}
In this paper we present the results of the intensive surveys and test pits carried out in the Superior Paraná Delta. The recorded sites $(\mathrm{n}=52)$ confirm the high archaeological potential of the area and they are integrated with the data base that compose the archaeological atlas of the Entre Ríos province. The information obtained in surface recoveries and test pits are summarized and the first radiocarbonic dates generated within the framework project are presented. The sites detected in the Superior Delta are articulated with the geomorphologic units proposed by Cavallotto et al. (2005) and the tendencies of study area indigenous occupation in relation to the space available during Late Holocene are briefly discussed. Finally, the elevated sites ("cerritos") are related to similar contexts in South American Lowlands.
\end{abstract}

$<$ Paraná River Delta $><$ Late Holocene $><$ Intensive surveys $><$ Mounds $>$ 


\section{Introducción}

El Delta del río Paraná ${ }^{1}$ fue una zona de interés arqueológico desde fines del siglo XIX hasta la actualidad, aunque con diferente intensidad en la dinámica de las investigaciones (véase por ejemplo Caggiano 1984; González 1947; Loponte et al. 2004; Lothrop 1932; Torres 1911; Zeballos y Pico 1878). Sin embargo, los estudios de las sociedades prehispánicas en el Delta Superior han sido muy escasos y discontinuos (Ambrosetti 1893; Gaspary 1950; Nóbile 2002). Salvo excepciones con un fuerte énfasis en los momentos posthispánicos (Rocchieti et al. 2007), en general han sido investigaciones puntuales (excavación de uno o dos sitios) y de corta duración. A partir del año 2005 esta situación comenzó a revertirse con el desarrollo de investigaciones sistemáticas y la ejecución de proyectos a largo plazo (Bonomo et al. 2007). El objetivo de este artículo es presentar los primeros resultados de los trabajos de campo y laboratorio del proyecto “Ocupaciones humanas prehispánicas en el Delta Superior del río Paraná (provincia de Entre Ríos)". Se sintetiza la información obtenida mediante las prospecciones intensivas, sondeos estratigráficos, relevamientos planimétricos y estudio de los materiales cerámicos, óseos y líticos provenientes de los trabajos de campo efectuados dentro del marco del proyecto.

A su vez, estos estudios contribuyen al atlas arqueológico de la provincia de Entre Ríos que está siendo elaborado por el Museo de Ciencias Naturales y Antropológicas "Prof. Antonio Serrano" en su carácter de autoridad de aplicación de Ley Provincial N ${ }^{\circ}$ 9686. Para su confección se siguen los lineamientos generales propuestos por Tarragó y Núñez Regueiro (1972), Tarragó y Díaz (1972; 1973), además de los aportes de Raviña y Callegari (1988), Poujade (1995), De Feo et al. (2002), Berón y Curtoni (2002). Con este atlas, que se está actualizando a medida que avanzan los estudios, se busca obtener un registro estandarizado de colecciones y sitios arqueológicos que facilite la protección del patrimonio cultural de Entre Ríos y sirva como marco para organizar las investigaciones de la provincia.

Por último, se analiza la distribución espacial de los sitios arqueológicos relevados durante los trabajos de campo en relación a la geomorfología del área siguiendo la propuesta de Cavallotto et al. (2005). Por lo tanto, en este trabajo se hará primero un resumen de las unidades geomorfológicas definidas por Cavallotto et al. (2005) y luego se las relacionará con los sitios registrados con el fin de detectar si existen algunas tendencias en la dinámica de ocupación indígena del Delta del Paraná y la evolución del paisaje durante el Holoceno.

\footnotetext{
${ }^{1}$ Utilizamos en sentido amplio esta denominación para referirnos a la llanura aluvial del río Paraná desde Diamante hasta su desembocadura en el Río de La Plata, ya que hay un larga tradición de uso de este término tanto en el campo de la arqueología (véase por ejemplo de Aparicio 1939) como en el de las ciencias naturales (Chiozza 1979). Sin embargo, recientemente Aceñolaza et al. (2008) utilizan el concepto de "Complejo Deltaico del río Paraná" que incluye el Delta propiamente dicho (desde Ibicuy hasta la desembocadura) y el Pre-Delta (desde Ibicuy hacia arriba hasta la diagonal Paraná-Santa Fe) y señala la continuidad ambiental de esta ecoregión.
} 


\section{Geomorfología}

La evolución ambiental del complejo deltaico, que incluye el Delta del Paraná y el Pre-Delta, es el producto de la interacción de diversos factores que actuaron desde el Pleistoceno final hasta el presente, como la dinámica costera, los cambios climáticos, las variaciones relativas del nivel del mar y la topografia del sustrato (Cavallotto 1995; Cavallotto et al. 2005; Iriondo 1980, 2004). Actualmente el frente del delta subaéreo se encuentra sometido a la dinámica del Río de la Plata, mientras que el resto del área está bajo la dinámica de inundaciones del río Paraná y secundariamente del principal afluente del delta, el río Gualeguay.

Cavallotto et al. (2005), modifican parcialmente el esquema propuesto por Iriondo $(1980,2004)$ y reconocen dos grandes ambientes morfológicos: 1) Pre-holoceno: llanura alta adyacente al Paraná que no fue afectada por la transgresión marina postglacial que inundó el curso inferior del río; 2) Holoceno: llanura costera entrerriana y el Delta del Paraná originados en momentos de cotas más elevadas del mar. La primera está constituida por una sucesión de llanuras de mareas, cordones litorales asociados a cordones de médanos y playas desarrolladas en un ambiente estuárico de aguas salobres durante la regresión marina. La segunda unidad se corresponde con el ambiente fluvial del río Paraná y está integrada por numerosas islas y cursos de agua.

Los depósitos holocénicos ubicados dentro del área estudiada en este trabajo se incluyen en los sistemas depositacionales de llanura costera y fluvial del Paraná. El sistema de llanura costera se divide en las siguientes facies:

- Facies de llanuras de mareas: depósitos limosos que apoyan discordantemente sobre la facies de estuario abierto y es sobrepuesta por la llanura con cordones de playa. Abarca el área deprimida del interior de la llanura costera y se caracteriza por la presencia de pantanos, bañados, cauces cortos y meandros. Su origen se vincula con un ambiente de mareas producto del abrigo de los cordones litorales durante el descenso marino que siguió al máximo transgresivo.

- Facies de llanuras con cordones de playas litorales y de cordones de médanos: ambas unidades se disponen paralelas a la costa. La primera está representada por depósitos arenosos de bermas que se extienden entre las llanuras de mareas y de playas, cuyas dataciones radiocarbónicas abarcan entre 6.550 y 5.180 años AP. Las cadenas de médanos se ubican por encima de la anterior con edades OSL de 1.610-2.980 años AP.

- Facies de llanuras de playas: se desarrolla entre las facies de cordones y el río Paraná y se compone por una serie de playas paralelas formadas a medida que descendía el mar. A partir de su orientación se diferencian dos sistemas, separados por llanuras de fangos en las que se desarrollan bañados. Su génesis se asocia con momentos de mayor disponibilidad de sedimentos fluviales y presenta edades radiocarbónicas de 2.565-1.730 años AP.

- Facies de llanura de mareas pre-deltaica: es un ambiente deprimido con depósitos finos desarrollado en el borde sur de la llanura costera. Actualmente se encuentra surcado por los cursos del Paraná y posee una edad mínima de 2.820 AP. 
Por su parte, el sistema depositacional fluvial del Paraná incluye las siguientes facies:

- Facies aluvial interior del río Paraná: sedimentos aluviales de edad reciente que progradan sobre ambas facies de llanuras de mareas, limitando por el oeste al sistema de llanura costera. Presenta cuerpos de agua no integrados entre sí, generados por eventos de inundación. Los cauces pequeños son activos sólo cuando las aguas de las grandes crecidas cubren por completo el sistema salvo las zonas elevadas como los albardones (véase Iriondo 2004).

- Facies aluvial del río Paraná: depósitos recientes producto de procesos aluviales dejados por la migración lateral de meandros. Corresponde a la unidad fajas de bancos y meandros de Iriondo (1980) que se originan durante las etapas finales de las crecientes. Durante las bajantes los bancos de arena son colonizados por especies arbóreas (sauces y alisos), que en nuevas inundaciones actúan como trampa sedimentaria.

En la actualidad todo este complejo litoral que se desarrolla en el área interna del Río de la Plata, presenta una activa dinámica, ya que periódicamente es anegado por el Paraná. Aún así, uno de los factores de inundación más importantes es el viento del sudeste (sudestada) que afecta sobre todo al delta, la llanura de playas y parte de la llanura de mareas o albúfera de Iriondo (2004). Otro efecto importante de los vientos del S y $\mathrm{SO}$ es la deflación del cordón litoral, formando dunas que migran hacia el norte sobre la llanura de mareas. Varios campos de dunas son producto de este proceso eólico, que muy probablemente esté influido por causas antrópicas modernas.

\section{Resultados}

La plataforma de inundación del río Paraná está sometida a eventos de inundaciones periódicas que dificultan la ocupación humana estable o prolongada de los sectores bajos y a la vez le restan visibilidad, resolución e integridad a los sitios producidos durante la ocupación de estas zonas cuando están emergidas. Por este motivo, en esta primera fase de los trabajos de campo se efectuaron prospecciones intensivas dirigidas principalmente hacia geoformas elevadas seleccionadas de acuerdo a la información cartográfica, ambiental, arqueológica y al conocimiento de los pobladores locales. Debido a que la constante depositación fluvial y la densidad de la cubierta vegetal reducen la visibilidad de los materiales arqueológicos, también se realizaron relevamientos al azar en zonas con cortes estratigráficos naturales y artificiales. La combinación de estas estrategias tuvo como finalidad optimizar las probabilidades de detección de la mayor cantidad y diversidad de sitios arqueológicos en el área de estudio.

A fines del año 2006 se iniciaron los trabajos de campo en las islas del río Paraná Inferior y su llanura adyacente, en el sector comprendido entre la desembocadura del arroyo de la Ensenada al norte y el río Paraná Pavón al sur. Como producto de las prospecciones llevadas a cabo se relevaron 52 sitios arqueológicos, lo que confirma el alto potencial arqueológico del área. Este grupo estaba formado por escasos sitios previamente publicados (Cerros de las Pajas Blancas, Grande de la isla de Los Marinos 
y El Castaño 1 y 2), por "cerritos" cuya existencia era ampliamente conocida en la zona (Los Tres Cerros, El Durazno, El Cerrito, etc.) y finalmente por otros identificados en las prospecciones. Los sitios se ubican en los departamentos de Diamante $(\mathrm{n}=9)$, Victoria $(\mathrm{n}=35)$ y Gualeguay $(\mathrm{n}=6)$ de la provincia de Entre Ríos y de San Jerónimo $(\mathrm{n}=2)$ de la de Santa Fe (Figura 1). Además, se han efectuado 27 sondeos estratigráficos de los cuales 20 proporcionaron sobre todo abundantes tiestos cerámicos. En marzo de 2008 se excavó el sitio Cerro Tapera Vázquez (Parque Nacional Pre-Delta), cuyos restos arqueológicos se encuentran en proceso de análisis. Asimismo, en el marco de un proyecto de cooperación internacional CSIC-CONICET, se realizaron 24 relevamientos planimétricos de alta resolución con Estación Total de una muestra de los sitios sobre montículos del sector de islas. Esto permitió elaborar modelos digitales de elevación. En base al análisis formal comparado de las planimetrías se comenzó a evaluar la presencia de patrones espaciales de los asentamientos y de áreas deprimidas y cerradas que podrían haber funcionado como de aporte de sedimento sobre los "cerritos" (Bonomo et al. 2007, 2008).

\section{Figura 1}

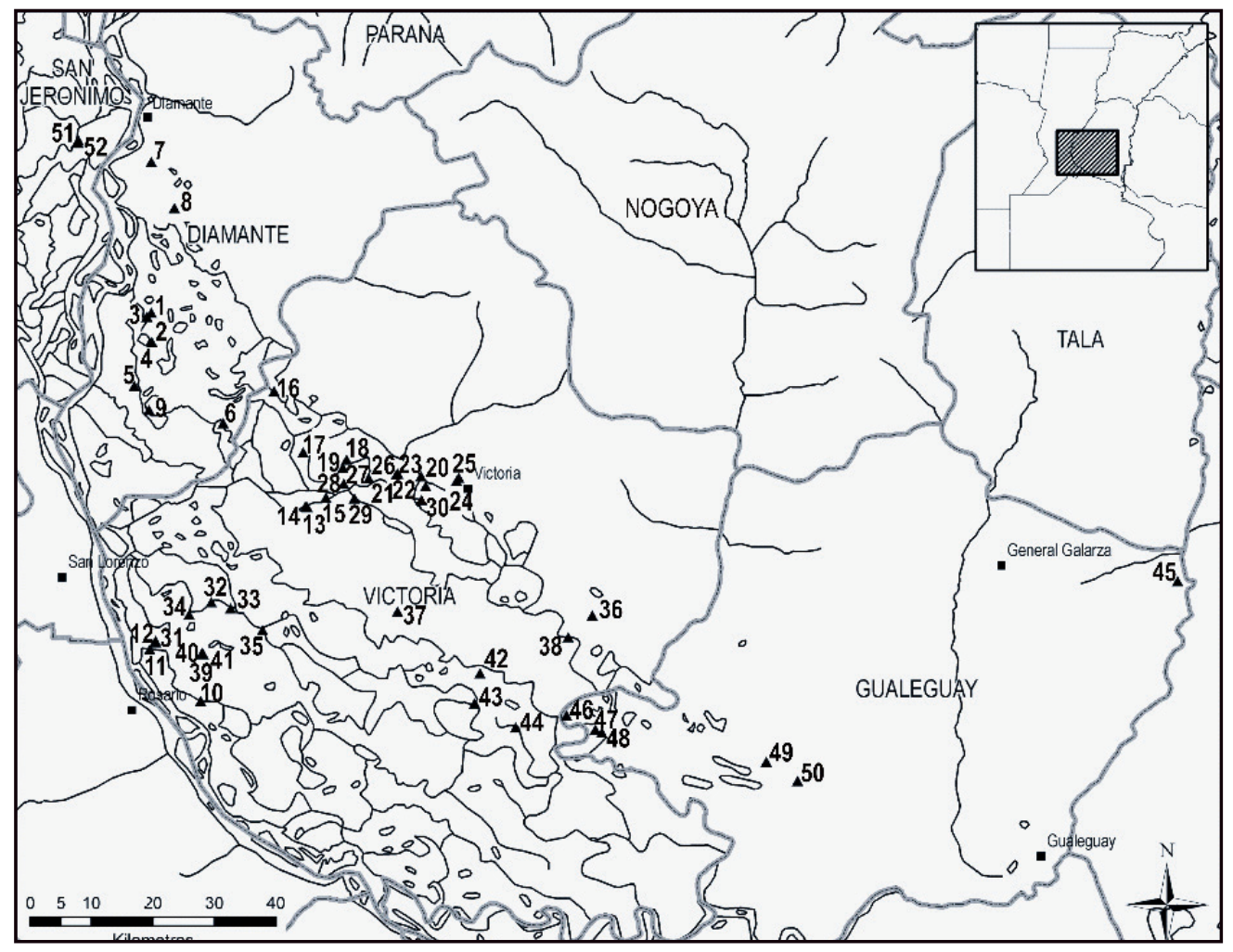

Mapa con los sitios arqueológicos relevados durante las prospecciones $\left(\mathrm{n}^{\mathrm{0}}\right.$ de los sitios tomados de las tablas 1 a 4 ) 
En las Tablas 1, 2, 3 y 4 se sintetiza la información de los sitios relevados. Para organizar los datos se utilizaron los códigos para la identificación de cada sitio propuestos por Tarragó y Núñez Regueiro (1972). De a acuerdo a ello y al sistema tetranominal, cada sitio se identifica con tres siglas y un número. La primera sigla indica el país (Argentina $=\boldsymbol{S}$ ) (Rowe 1971), la segunda la provincia (Entre Ríos $=\boldsymbol{E n t}$ ) y la tercera corresponde a la denominación de los tres departamentos provinciales incluidos en este artículo $($ Diamante $=\boldsymbol{D i a} ;$ Victoria $=\boldsymbol{V i c}$ y Gualeguay $=\boldsymbol{G} \boldsymbol{u a})($ Castro 2007). El número ordena los sitios por departamento de manera correlativa según la antigüedad de su hallazgo o fecha de publicación. Separado por un guión se agrega un segundo número (0 si se realizó recolección superficial o $\mathbf{1}$ si se efectuaron sondeos estratigráficos o excavaciones). Para cada sitio codificado además se consigna en las tablas su nombre, coordenadas geográficas, topografía, curso o cuerpo de agua más cercano, trabajos realizados por el equipo de investigación (relevamientos planimétricos, sondeos estratigráficos con restos arqueológicos, recolección de muestras de materiales superficiales), clases de materiales arqueológicos registrados hasta el momento y referencias bibliográficas.

\section{Descripción contextual de los sitios}

Las prospecciones se llevaron a cabo tanto en el sector de islas como también en el de llanuras adyacentes. En el sector de llanura se efectuó un recorrido pedestre de las barrancas del río Gualeguay $(1,5 \mathrm{~km})$, de los arroyos Tremendo $(1 \mathrm{~km})$, Barrancoso (1 $\mathrm{km})$, Doll $(0,5 \mathrm{~km})$ y de la Ensenada $(6 \mathrm{~km})$, así como en cortes artificiales, detectándose cinco sitios arqueológicos. Entre los sitios detectados en este sector de tierra firme, se destacan por su importancia dos que se describen a continuación:

Cerro La Matanza 2: en la cima del cerro homónimo, tanto en el camino de ascenso como en sedimentos de cuevas de tuco-tuco (Ctenomys sp.), inicialmente se recuperaron 23 restos óseos, gran parte de los cuales estaban termoalterados. Se efectuó un sondeo de 0,6 $\mathrm{m}$ de profundidad en el que se hallaron cinco tiestos de cerámica lisa, un fragmento de un posible tortero sobre loza esmaltada, un desecho lítico, dos fragmentos de vidrio y 2293 restos óseos de fauna autóctona (coipo, dasipódidos y moluscos de agua dulce) e introducida (vaca o caballo, oveja y aves) con un alto grado de fragmentación y alteración térmica. Las características del contexto señalan que el área sondeada del sitio correspondería a un basurero de momentos post-hispánicos.

Médano El Pencal: ubicado sobre un cordón de médanos donde se halló material arqueológico disperso, sobre todo en los lugares donde pastorea el ganado. En la superficie del terreno se registraron 220 fragmentos de cerámica lisa, cinco materiales líticos y tres restos óseos. Según la información brindada por pobladores locales, esta acumulación ha sufrido una disminución de tamaño debido a la extracción de abundantes cantidades de arena para la construcción. Durante esas actividades se halló una mandíbula humana. 
Folia Histórica del Nordeste, № 18 (Resistencia, 2010) IIGHI, CONICET - IH, UNNE

\begin{tabular}{|c|c|c|c|c|c|c|c|c|c|}
\hline 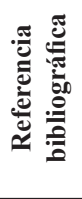 & 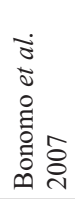 & 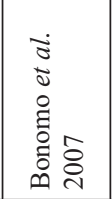 & 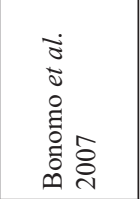 & 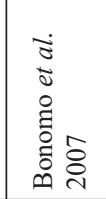 & 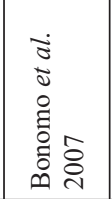 & 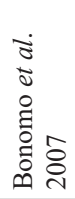 & 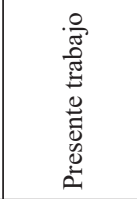 & 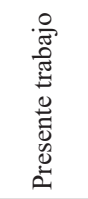 & 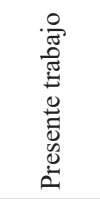 \\
\hline 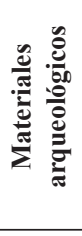 & 岂 & 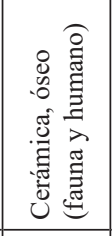 & 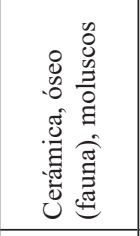 & 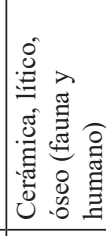 & 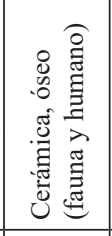 & 营 & 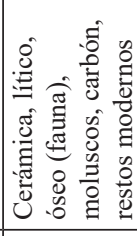 & 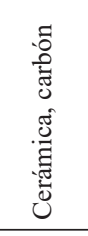 & 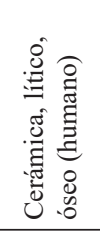 \\
\hline 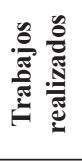 & 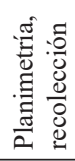 & 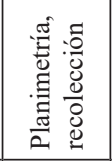 & 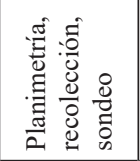 & 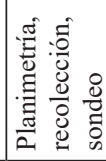 & 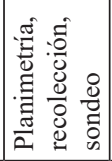 & 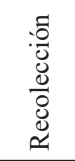 & 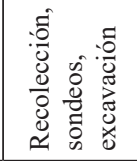 & 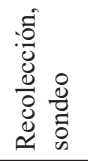 & 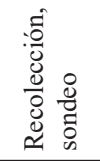 \\
\hline 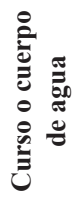 & 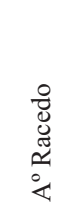 & 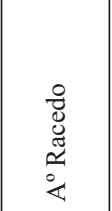 & 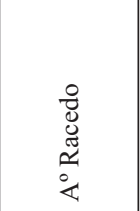 & 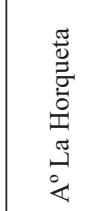 & 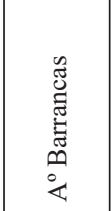 & 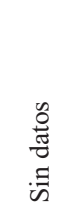 & $\begin{array}{l}8 \\
\stackrel{0}{0} \\
0 \\
\text { II } \\
0 \\
\&\end{array}$ & 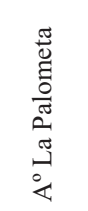 & 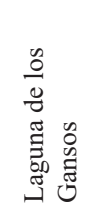 \\
\hline 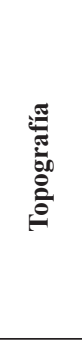 & 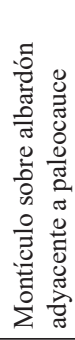 & 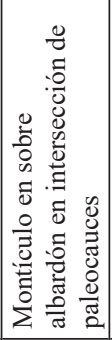 & 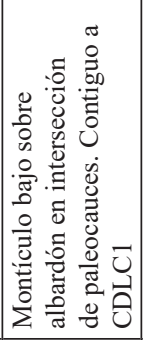 & 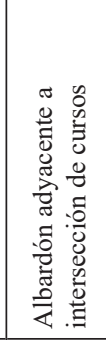 & 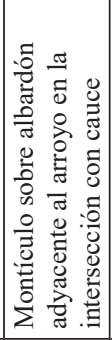 & 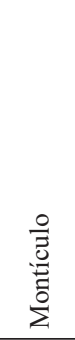 & 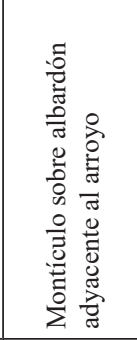 & 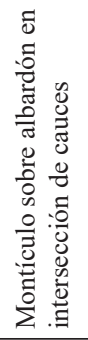 & 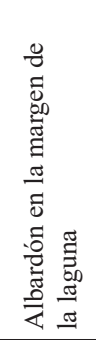 \\
\hline 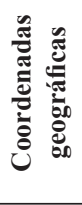 & 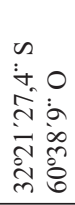 & $\begin{array}{ll}n & 0 \\
\vdots & 0 \\
-1 & 0 \\
0 & = \\
n & \infty \\
\pi & \infty \\
0 & 0 \\
i & 0\end{array}$ & 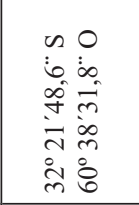 & 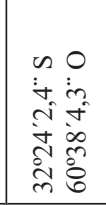 & 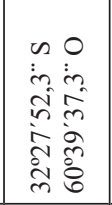 & 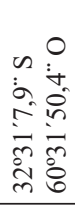 & 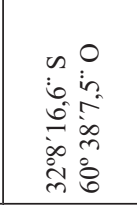 & $\begin{array}{ll}\infty & 0 \\
\infty & 0 \\
\infty & \vdots \\
\infty & 0 \\
\vec{i} & 0 \\
0 & 0 \\
0 & 0\end{array}$ & 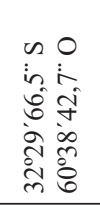 \\
\hline 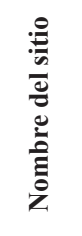 & 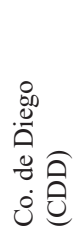 & 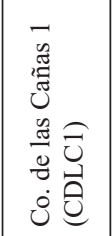 & 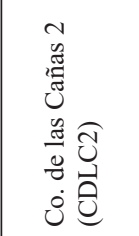 & 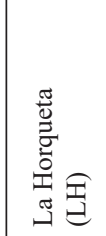 & 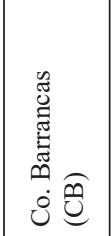 & 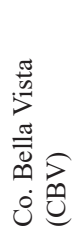 & 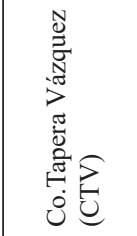 & 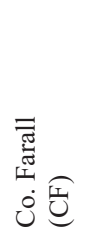 & 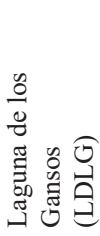 \\
\hline 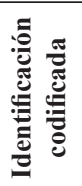 & 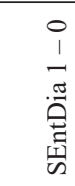 & 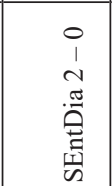 & 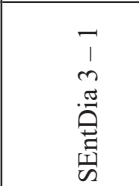 & 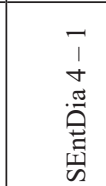 & 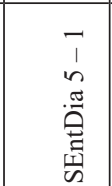 & 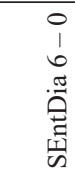 & 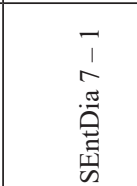 & 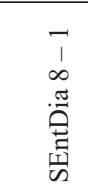 & 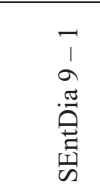 \\
\hline 设 & - & $N$ & $m$ & t & $n$ & 0 & $r$ & $\infty$ & $a$ \\
\hline
\end{tabular}


Bonomo, Politis y Castro. Investigaciones arqueológicas en el delta superior del paraná

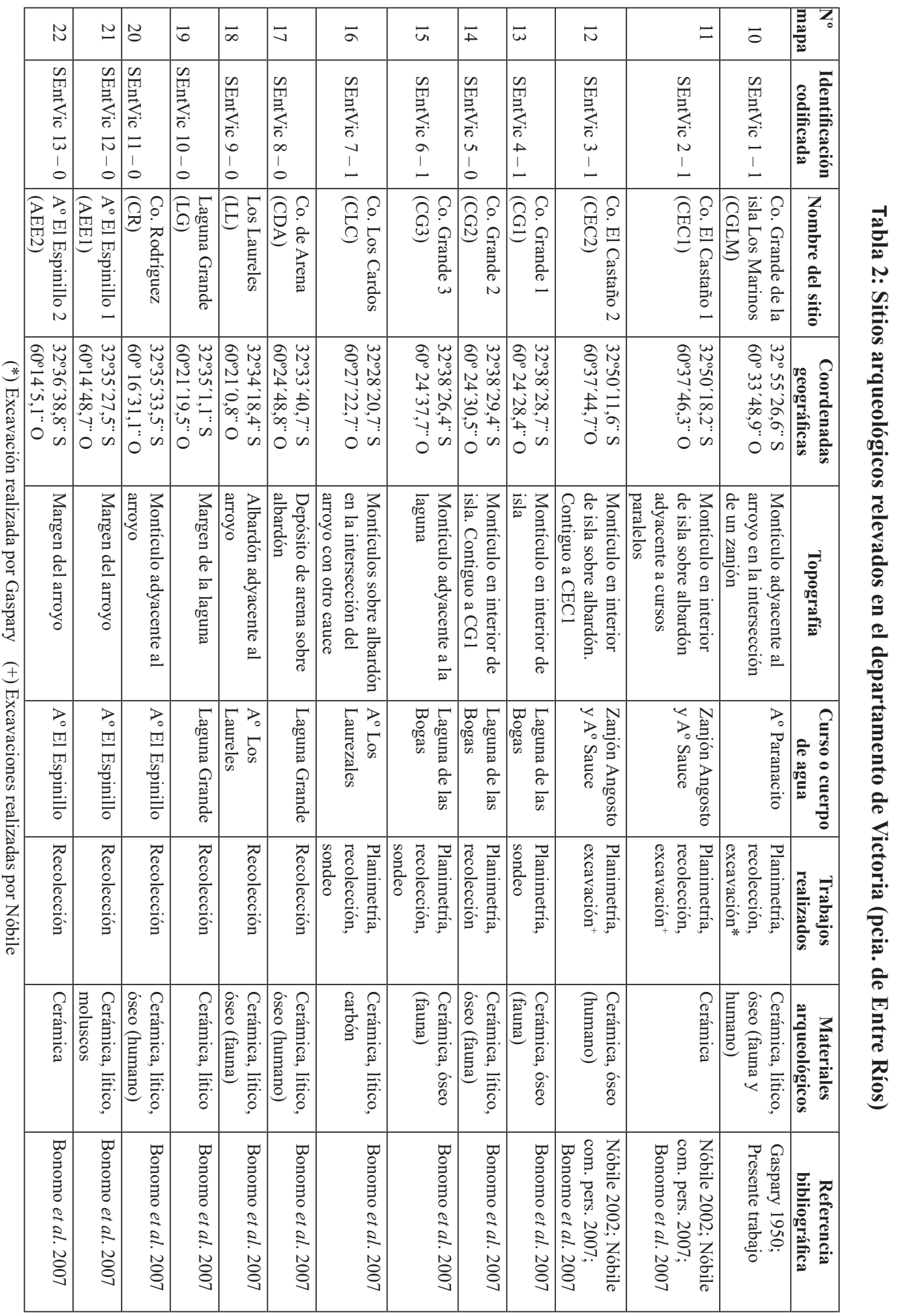


Folia Histórica del Nordeste, № 18 (Resistencia, 2010) IIGHI, CONICET - IH, UNNE

\begin{tabular}{|c|c|c|c|c|c|c|c|c|c|c|c|c|c|c|}
\hline 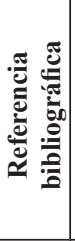 & 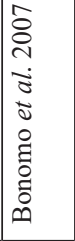 & 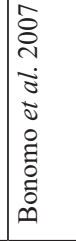 & 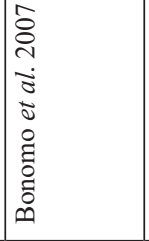 & 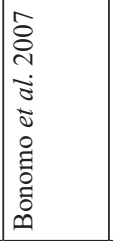 & 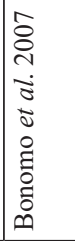 & 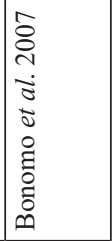 & 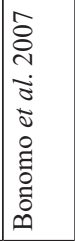 & 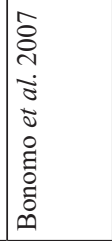 & 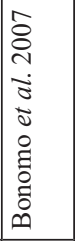 & 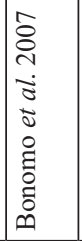 & 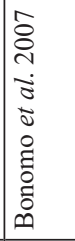 & 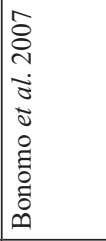 & 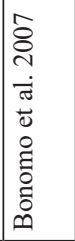 & 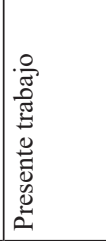 \\
\hline 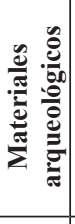 & 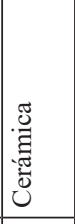 & 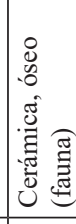 & 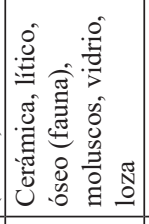 & 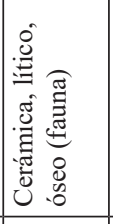 & 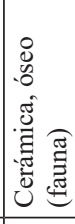 & 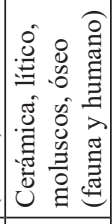 & Uू. & 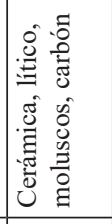 & 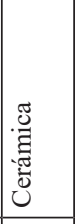 & 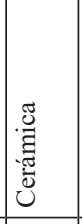 & 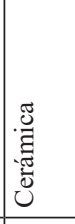 & 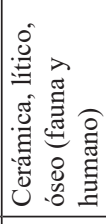 & 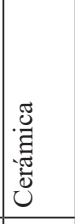 & 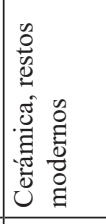 \\
\hline 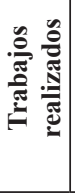 & 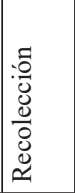 & 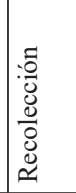 & 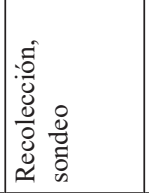 & 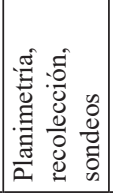 & 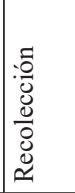 & 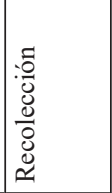 & 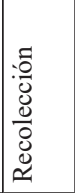 & 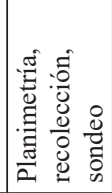 & 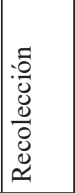 & 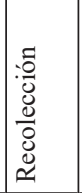 & 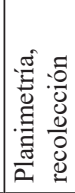 & 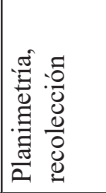 & 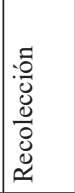 & 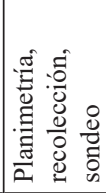 \\
\hline 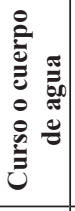 & 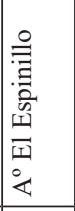 & 1 & I & 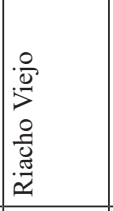 & 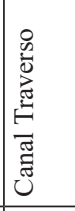 & 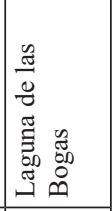 & 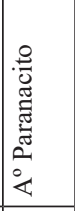 & 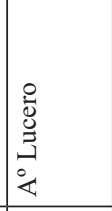 & 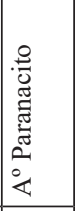 & 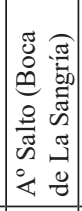 & 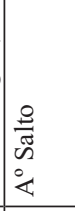 & \begin{tabular}{l}
$\frac{8}{\pi}$ \\
$\tilde{n}$ \\
\hdashline \\
\hdashline
\end{tabular} & 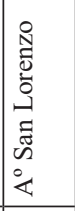 & 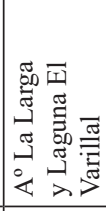 \\
\hline 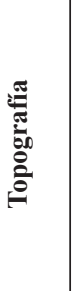 & 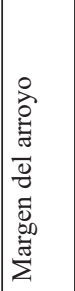 & 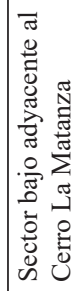 & 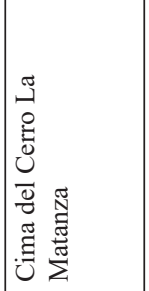 & 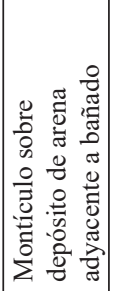 & 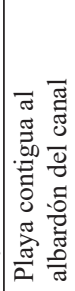 & 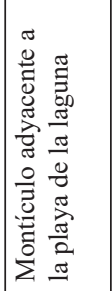 & 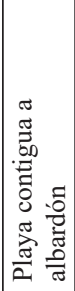 & 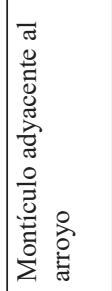 & 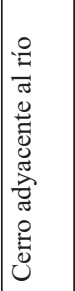 & 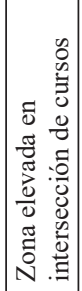 & 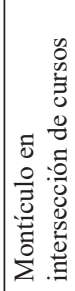 & 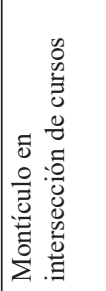 & 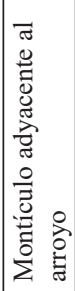 & 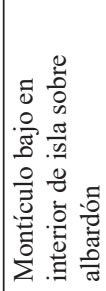 \\
\hline $\begin{array}{ll}0 \\
0\end{array}$ & 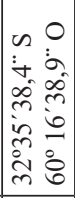 & 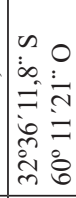 & 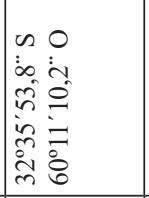 & 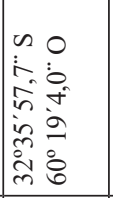 & 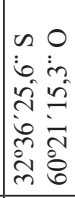 & 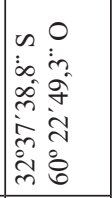 & 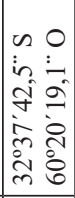 & 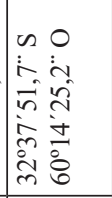 & 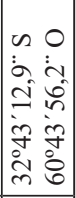 & 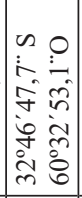 & 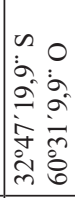 & 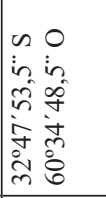 & 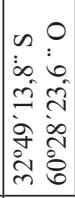 & 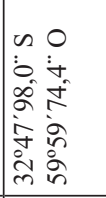 \\
\hline 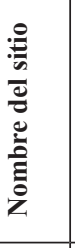 & 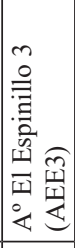 & 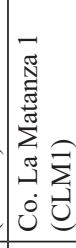 & 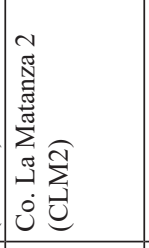 & 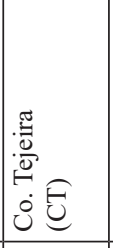 & 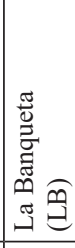 & 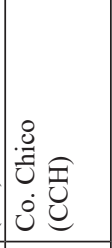 & 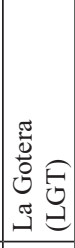 & 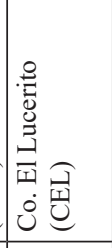 & 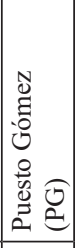 & 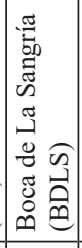 & 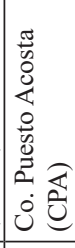 & 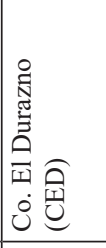 & 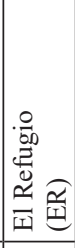 & 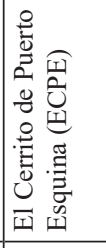 \\
\hline 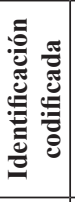 & 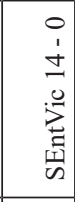 & $\begin{array}{l}0 \\
1 \\
n \\
0 \\
0 \\
0 \\
\text { 恶 }\end{array}$ & 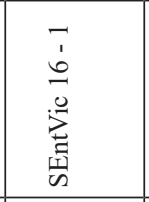 & 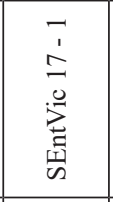 & 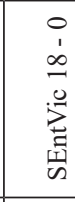 & 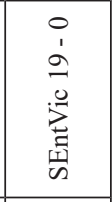 & 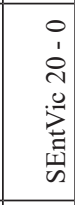 & 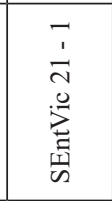 & 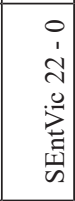 & 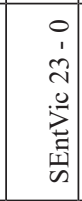 & 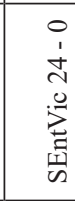 & 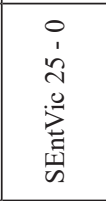 & 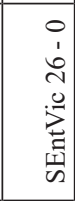 & 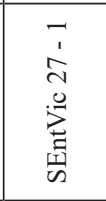 \\
\hline ¿ & & d & $\ddot{\sim}$ & $\stackrel{\sim}{\sim}$ & $N$ & $\stackrel{\infty}{\sim}$ & ते & in & $\vec{m}$ & $\tilde{m}$ & $m$ & ఫ্ & $m$ & ల \\
\hline
\end{tabular}


Bonomo, Politis y Castro. Investigaciones arqueológicas en el delta superior del paraná

\begin{tabular}{|c|c|c|c|c|c|c|c|c|}
\hline 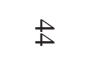 & $\stackrel{\vec{\omega}}{ }$ & N & \pm & t & $\underline{\sigma}$ & $\omega_{\infty}^{\omega}$ & $\underset{v}{w}$ & $Z_{0}$ \\
\hline 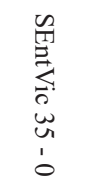 & 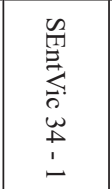 & 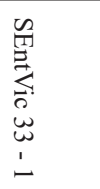 & 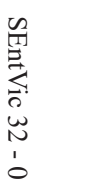 & 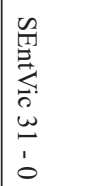 & 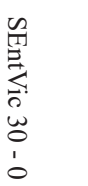 & \begin{tabular}{l}
$n$ \\
T. \\
\multirow{2}{*}{} \\
0 \\
N \\
1 \\
1
\end{tabular} & 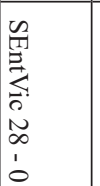 & 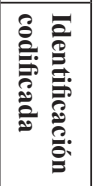 \\
\hline 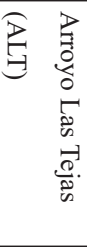 & 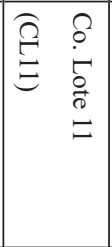 & 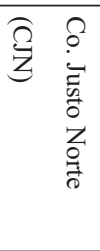 & 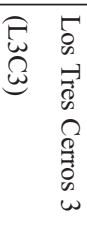 & 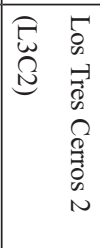 & 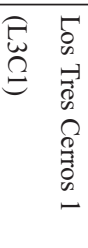 & 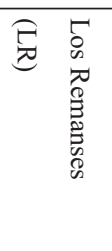 & 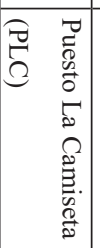 & 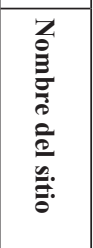 \\
\hline 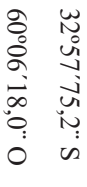 & 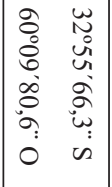 & 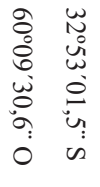 & 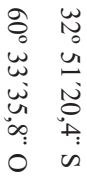 & 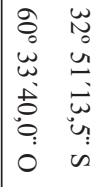 & 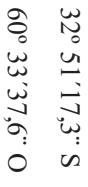 & 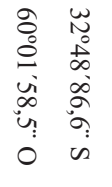 & 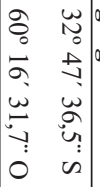 & 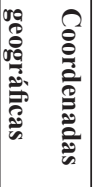 \\
\hline 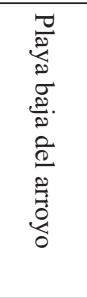 & 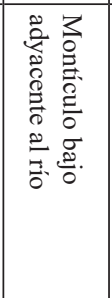 & 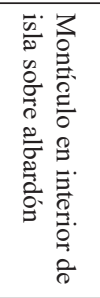 & 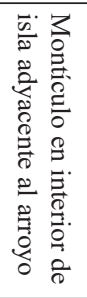 & 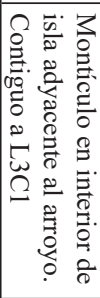 & 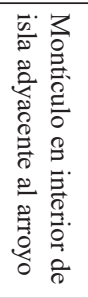 & 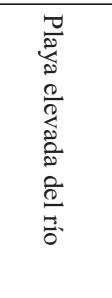 & 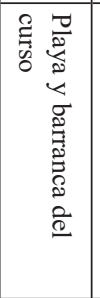 & 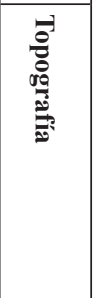 \\
\hline 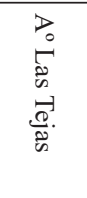 & 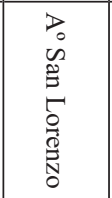 & 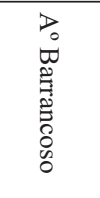 & 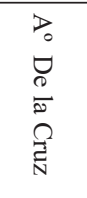 & 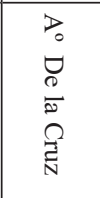 & $\begin{array}{l}D_{0} \\
\ddot{0} \\
0 \\
\stackrel{2}{2} \\
\tilde{N} \\
\tilde{N}\end{array}$ & 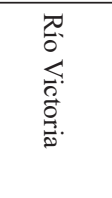 & 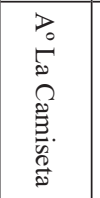 & 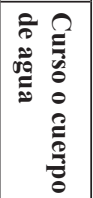 \\
\hline 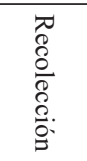 & 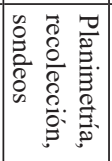 & 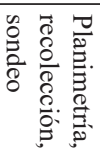 & 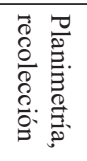 & 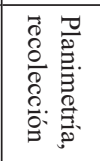 & 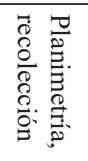 & 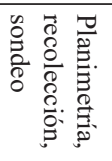 & 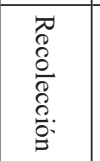 & 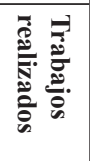 \\
\hline 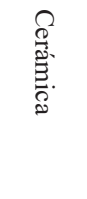 & 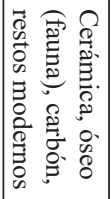 & 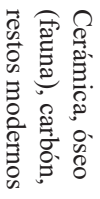 & 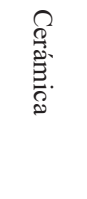 & . & 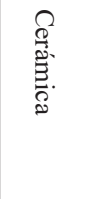 & 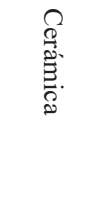 & $\begin{array}{l}\text { Q } \\
\stackrel{3}{3} \\
\text { S. }\end{array}$ & 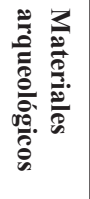 \\
\hline 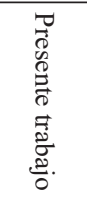 & 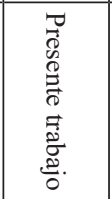 & 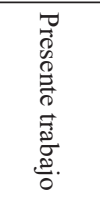 & 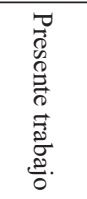 & 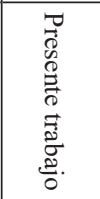 & 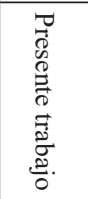 & 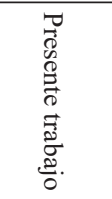 & 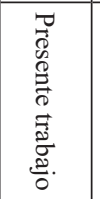 & 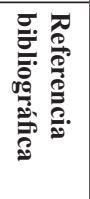 \\
\hline
\end{tabular}


Folia Histórica del Nordeste, № 18 (Resistencia, 2010) IIGHI, CONICET - IH, UNNE
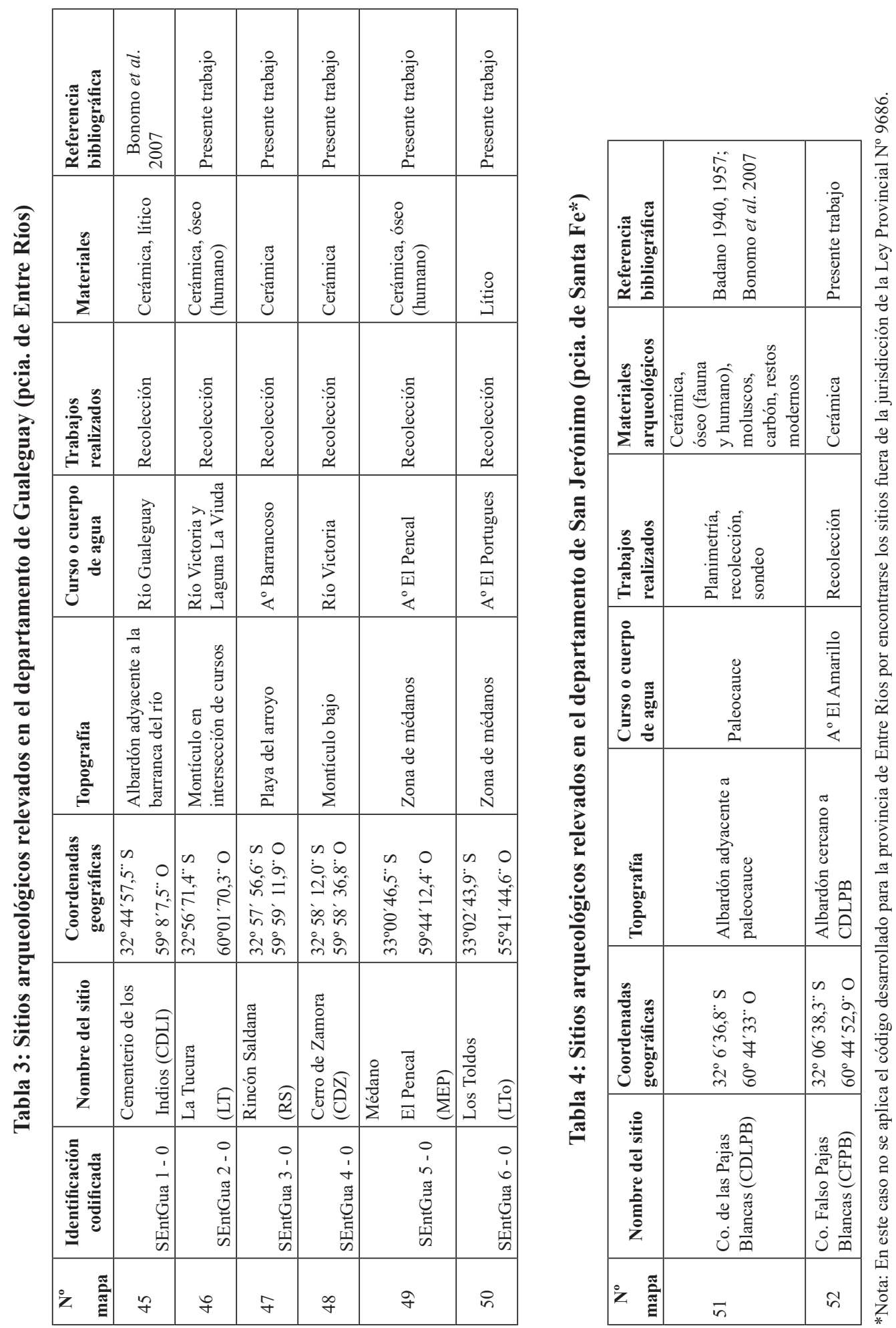
En el sector de islas se registraron 47 sitios arqueológicos, en su mayoría localizados en las zonas más elevadas respecto a las áreas circundantes. La frecuente vegetación arbórea (laurel, curupí, sauce, timbó, ceibo, tártago) y los matorrales de espinillos que crecen encima de estos lugares estables del paisaje facilitan la visibilidad y por lo tanto la detección de los sitios. Dentro de los sitios relevados, los principales contextos son los siguientes:

Cerro de Diego: montículo bordeado por un madrejón (cauce inactivo) en el interior de la isla de las Cuatro Bocas. Se localiza a $883 \mathrm{~m}$ de distancia hacia el NE de Cerro de las Cañas 2. En posición superficial se recuperaron 22 fragmentos de cerámica lisa y un apéndice, parte de los cuales muestran fracturas frescas producidas por el pisoteo del ganado.

Cerro de las Cañas 1 y 2: localizados en la intersección de dos cauces inactivos perpendiculares en la isla de las Cuatro Bocas en las proximidades del arroyo Racedo. Ambos sitios se ubican sobre un albardón discontinuo que se extiende paralelo a uno de los paleocauces. Este albardón fue seccionado por el otro paleocauce, quedando a ambos lados cada uno de los sitios, separados por $46 \mathrm{~m}$ de distancia. En el montículo del Cerro de las Cañas 1 se recuperaron 46 restos faunísticos y 26 tiestos lisos en la superficie del terreno descubierta de vegetación herbácea por la acción del ganado vacuno. El Cerro de las Cañas 2 está constituido por una pequeña elevación en la que se hallaron 30 restos faunísticos y 45 tiestos lisos procedentes de un sondeo de $0,4 \mathrm{~m}$ de profundidad. Es importante agregar que del sitio 1 un nutriero de la zona extrajo dos esqueletos humanos.

La Horqueta: albardón en la intersección de dos brazos activos del arroyo La Horqueta en la isla de las Cuatro Bocas. Un sector del sitio ha sido erosionado por la migración lateral de uno de estos brazos. En la superficie del terreno se hallaron tres materiales líticos, 10 restos faunísticos (entre ellos de coipo Mycoastor coypus), 173 fragmentes de alfarería lisa, incisa y pintada de rojo. En el sondeo efectuado de 0,4 m de profundidad se recuperaron tres restos faunísticos y ocho tiestos lisos. De este sitio un poblador extrajo dos esqueletos humanos que afloraban en la barranca.

Cerro Barrancas: montículo sobre albardón en la intersección del arroyo Barrancas con un paleocauce en las proximidades de la laguna de los Engaces en la isla Barrancas Coloradas. Está altamente modificado por la presencia de un puesto y un corral en el que el pisoteo vacuno ha provocado un descenso promedio de $0,3 \mathrm{~m}$ de la superficie del terreno. En la superficie se recuperaron seis restos faunísticos, 63 fragmentos cerámicos lisos, incisos y modelados (apéndices zoomorfos). Se realizó un sondeo de $0,5 \mathrm{~m}$ de profundidad en el que se registraron 212 fragmentos cerámicos lisos, incisos, pintados (rojo y blanco) y modelados (apéndices) y 21 restos faunísticos, entre los que se identificaron restos de coipo y lobito de río (Lontra sp.). Previamente al relevamiento efectuado, los habitantes del puesto habían hallado restos óseos humanos, un puco entero y una posible cuchara de cerámica.

Cerro Tapera Vázquez: montículo sobre albardón adyacente al arroyo El Ceibo que lo ha erosionado parcialmente. El montículo se eleva $3 \mathrm{~m}$ por encima del nivel del 
arroyo y $1 \mathrm{~m}$ del albardón. A partir del relevamiento de los perfiles de la barranca y de pruebas de pala a lo largo del albardón se pudo determinar que el material arqueológico se extiende por $102 \mathrm{~m}$ de longitud. En la zona más elevada, en la parte superior de su secuencia estratigráfica están enterrados los vestigios de un puesto de mediados del siglo XX (ladrillo, metal, huesos de fauna introducida aserrados, etc.). Allí, en un sondeo de $0,75 \mathrm{~m}$ de profundidad se recuperaron 108 tiestos de cerámica lisa e incisa, 82 materiales faunísticos (coipo, peces, moluscos de agua dulce, etc.), espículas de carbón y posibles fragmentos de arcilla cocida. En este sitio se excavaron $16 \mathrm{~m}^{2}$, donde se recuperaron abundantes materiales cerámicos lisos, incisos y modelados (asas y apéndices), entre los que se destacan una "cuchara" con espículas de carbón en su interior, un asa zoomorfa y un apéndice que podría atribuirse a la cabeza de un tapir. Asociados a la alfarería, se registró una mano de mortero con evidencias de uso de dos de sus caras y restos óseos de coipos (taxa dominante), ciervo de los pantanos (Blastocerus dichotomus), carnívoros, roedores, peces, etc. Además se identificaron huesos con fractura helicoidal, huellas de corte, termoalteración y un desecho de manufactura de un instrumento. En este sitio se obtuvieron dos dataciones radiocarbónicas sobre carbón de la cuadrícula 2 que arrojaron las siguientes edades: $650 \pm 60$ (Nivel: $1,25-1,35$ m; LP-1989) y $520 \pm 60$ años AP (Nivel: 1,50-1,60 m; LP-1993).

Cerro Farall: montículo sobre un albardón en la intersección de un paleocauce con el arroyo La Palometa en las inmediaciones del Parque Nacional Pre-Delta. Se encuentra alterado por la acción fluvial y el pisoteo del ganado que eliminó la vegetación herbácea de la superficie donde se registraron 28 tiestos de cerámica lisa. Se realizó un sondeo de $0,45 \mathrm{~m}$ de profundidad en el que se recuperaron 349 fragmentos de alfarería lisa e incisa, cuatro restos óseos (entre ellos de peces), espículas de carbón y clastos posiblemente sometidos a la acción del fuego.

Laguna de los Gansos: se emplaza en el albardón oeste de la laguna de Los Gansos y posee una extensión $142 \mathrm{~m}$. La recolección superficial del material arqueológico se sectorizó en cuatro unidades de muestreo (sectores 1, 2, 3 y 4), siendo el sector 4 el más elevado y donde se observó la mayor concentración de piezas. Se recuperaron 205 fragmentos de cerámica lisa, incisa y modelada (asas, "campana"), 83 restos óseos (coipo, cérvido y humanos) y tres restos líticos (manos). En un sector adyacente a un puesto, en donde hay varios corrales, los lugareños recolectaron alfarería y restos óseos humanos.

Cerro Grande de la isla de Los Marinos: montículo adyacente al arroyo Paranacito en la intersección con el zanjón de la Raya. Se recuperaron 27 tiestos lisos y dos restos líticos en la superficie despejada de vegetación por el ganado. También se encuentra alterado por el accionar de aficionados y con anterioridad hubo un rancho sobre el cerro y su superficie fue arada. F. Gaspary (1950) excavó este sitio, donde halló 48 esqueletos humanos, parte de los cuales estaban recubiertos con pigmento rojo. Los huesos humanos se registraron en entierros primarios, paquetes funerarios, dispersos y calcinados. Además, recuperó numerosa alfarería lisa, incisa, impresa, unguiculada, pintada y modelada ("campanas", cucharas, torteros, apéndices zoomorfos, adornos, etc.), instrumentos óseos y líticos no tallados y restos faunísticos (yaguareté, ciervo de los 
pantanos, coipo, peces y valvas de moluscos). Parte de los materiales de estos trabajos se encuentran depositados en los museos del Paraná y las Islas e Histórico Provincial "Dr. Julio Marc" de Rosario.

Cerro El Castaño 1 y 2: ambos sitios fueron excavados por el Mgs. J. Nóbile en la década de 1990. Se tratan de dos montículos, sobre un probable albardón, ubicados entre los cursos Zanjón Angosto y El Sauce y rodeados de bañados. Sobre el sitio 1 anteriormente estaba emplazado un puesto. Allí, se recuperaron ocho tiestos lisos. El sitio 2 se encuentra rodeado por un cauce inactivo. Ambos sitios están separados por $207 \mathrm{~m} \mathrm{y}$ entre ambos hay una depresión discreta de forma cuadrangular que podría ser un área de reclame de sedimentos. Además, se registraron otras áreas elevadas en los alrededores de ambos cerros. En El Castaño 2 Nóbile halló ocho esqueletos humanos, siete en paquetes funerarios y uno en posición decúbito dorsal, extendido y en relación anatómica. Obtuvo una datación radiocarbónica en el LATYR (FCNyM; UNLP) de un fémur del esqueleto extendido de $890 \pm 70$ años AP (Juan Nóbile com. pers. 2007).

Cerro Grande 1, 2 y 3: montículos ubicados en la isla del Pillo, tanto en un sector interno (C. Grande 1 y 2) como en las adyacencias de la laguna de las Bogas (C. Grande 3). Los sitios 1 y 2 están separados entre sí por solo $58 \mathrm{~m}$ y del sitio 3 por $209 \mathrm{~m}$. El material recuperado en Cerro Grande 1 proviene de un sondeo de $0,3 \mathrm{~m}$ de profundidad donde se hallaron tres restos faunísticos, entre los que se identificaron restos de coipo, y 24 fragmentos de cerámica lisa y pintada. En Cerro Grande 2 se registraron los siguientes materiales en posición superficial: un instrumento lítico, dos restos faunísticos (uno de vaca), 39 tiestos de alfarería lisa e incisa. En la superficie del terreno de Cerro Grande 3 se hallaron dos restos faunísticos (uno de coipo) y 33 fragmentos de cerámica lisa. En este sitio se efectuó un sondeo de $0,4 \mathrm{~m}$ de profundidad en el que se registraron tres restos faunísticos y 34 tiestos lisos. En esta localidad han sido halladas "campanas" de cerámica por el personal del Museo Arqueológico y Paleontológico Municipal de Victoria. Además, en la isla donde se ubican estos cerros fue hallada una urna funeraria corrugada (Badano 1940).

Cerro Los Cardos: montículos localizados en la intersección del arroyo Laurezal con un cauce que formaba un bañado con aguas estancadas. Sobre la superficie libre de hierbas se recuperaron dos materiales líticos y 14 tiestos lisos e incisos. Además, se efectuó un sondeo de $0,5 \mathrm{~m}$ de profundidad en este sitio, donde se hallaron un rodado $\sin$ modificación antrópica, 339 tiestos lisos, inciso, con restos de pintura (roja y negra) y un asa de cerámica, así como abundantes espículas de carbón.

Cerro de Arena: ubicado sobre una acumulación de arena, parcialmente vegetada con hierbas y matorrales, que se encuentra depositada sobre un albardón paralelo a la laguna Grande y adyacente a un bañado interno. El material arqueológico se halló a lo largo de unos $150 \mathrm{~m}$ sobre la playa de la laguna y en los sedimentos arenosos, tanto en superficie como semi-enterrados. El mismo se recuperó en dos unidades de muestro (sectores 1 y 2). Se halló una lasca y 303 fragmentos de cerámica lisos e incisos (incluida una masa de arcilla). La acción del agua y el pisoteo del ganado sobre el sitio se reflejan 
en la presencia de tiestos de tamaños pequeños con bordes redondeados y/o con fracturas frescas in situ. En las inmediaciones de este sitio han sido hallados por el personal del Museo Arqueológico y Paleontológico Municipal de Victoria esqueletos humanos, apéndices zoomorfos y esferoides de piedra con surco que podrían ser bolas de boleadora y/o pesas para redes.

Los Laureles: albardón subparalelo a la dirección del arroyo Los Laureles y adyacente a una zona baja interna con pajonales. El material fue recuperado por medio de cuatro unidades de recolección (sectores 1, 2, 3 y 4) trazadas a lo largo de los $675 \mathrm{~m}$ que posee la distribución de los materiales arqueológicos. La erosión fluvial ha generando una barranca discontinua que no supera $\operatorname{los} 0,5 \mathrm{~m}$ de altura que ha sido alterada por roedores con hábitos fosoriales. Como consecuencia de la acción de estos agentes el material arqueológico ha sido depositado sobre la playa del arroyo, donde se recuperaron 30 materiales líticos (16 son instrumentos), 126 fragmentos cerámicos, tanto lisos, incisos, pintados (rojo), modelados, asas como también masas de arcilla. En este sitio un poblador y personal del Museo Arqueológico y Paleontológico Municipal de Victoria han recuperado numerosos materiales arqueológicos, entre los que se destacan vasijas enteras, una "campana", una cuchara, apéndices zoomorfos, tiestos corrugados y orejeras.

Cerro Rodríguez: albardón paralelo a la margen del arroyo El Espinillo y adyacente a un bajo interno con pajonales. Al momento del relevamiento poseía una ranchada de pescadores sobre el sitio. En la superficie del terreno se hallaron nueve artefactos líticos (dos instrumentos) y 57 fragmentos de alfarería lisos, incisos, pintados y un asa. En un zanjón contiguo al sitio han sido extraídos esqueletos humanos por el personal del Museo Arqueológico y Paleontológico Municipal de Victoria.

Cerro Tejeira: montículo de arena localizado en la isla Corte Viejo, adyacente a un bañado que se conecta con la laguna El Recado durante las crecientes. El montículo está desprovisto de vegetación herbácea, ya que posee un puesto encima con varias instalaciones. En la superficie del terreno se hallaron 6 materiales líticos, 6 restos faunísticos, 57 tiestos lisos, un asa, un apéndice y una masa de arcilla. Se realizaron dos sondeos que alcanzaron una profundidad máxima de $0,8 \mathrm{~m}$, donde se hallaron 8 restos faunísticos y 11 tiestos lisos.

Cerro Chico: sector elevado contiguo a la laguna de las Bogas en la isla del Pillo. El material arqueológico se halla en un paleosuelo que aflora en una barranca baja y disperso sobre la playa de la laguna. Se recuperaron en la superficie del terreno 5 materiales líticos (tres instrumentos), 4 restos faunísticos y 17 tiestos lisos e incisos y un asa de cerámica. En este sitio han sido hallados esqueletos humanos por el personal del Museo Arqueológico y Paleontológico Municipal de Victoria.

Cerro El Lucerito: montículo adyacente al arroyo El Lucero. Sobre la superficie se recuperó una concreción calcárea con valvas y 11 tiestos de alfarería lisa. Se efectuó un sondeo de $0,6 \mathrm{~m}$ de profundidad, donde se recuperaron 34 tiestos lisos, incisos, pintados y unguiculados y espículas de carbón. En este sitio el dueño de la propiedad halló una cuchara de cerámica. 
Boca de la Sangría: zona elevada con vegetación herbácea en la intersección de los arroyos Salto y La Sangría. Los materiales arqueológicos se distribuyen a lo largo de unos $86 \mathrm{~m}$. La acción fluvial ha conformado una barranca donde afloran los materiales en un paleosuelo. Allí se hallaron 28 tiestos lisos, incisos y pintados y una masa de arcilla.

Cerro Puesto Acosta: montículo en la intersección del arroyo Salto con el San Lorenzo. Posee un puesto con corrales encima del montículo y está siendo afectado por la erosión fluvial que ha conformado una barranca. Los materiales arqueológicos se hallan tanto sobre el montículo como en el perfil de la barranca. Se recuperaron 75 tiestos lisos e incisos.

Cerro El Durazno: montículo en la intersección del arroyo Salto con un paleocauce (que a su vez posee un brazo que rodea el sitio) en la isla El Durazno. El sitio posee un puesto con corrales encima. El material se registró en la superficie del terreno y en estratigrafía en una superficie de estabilización sobre el perfil de la barranca. Se recuperaron un desecho lítico, 272 fragmentos de alfarería lisa, incisa, pintada de rojo, corrugada, modelada, asas y masas de arcilla y 29 restos óseos, entre los que se identificaron un incisivo humano y restos de coipo, carpincho, ciervo de los pantanos y peces (siluriformes).

El Cerrito de Puerto Esquina: montículo erosionado sobre un relicto de albardón en el interior de la isla El Cerrito. Según la información brindada por los pobladores de la zona, el montículo antes tenía una altura mayor que fue reducida por la erosión fluvial y las alteraciones generadas por un puesto ganadero. En un sondeo, con hallazgos solo en la capa superior, y en la superficie de la playa se recuperaron 39 materiales cerámicos lisos, incisos y modelados, 25 líticos (un instrumento) y siete restos óseos de cérvidos y mamíferos indet. (algunos mineralizados), así como también fragmentos de ladrillos, vidrio y loza. Docentes y alumnos de la Escuela No 28 "Juvenilia" del Paraje Puerto Esquina recolectaron en el sitio abundantes fragmentos de cerámica, incluidos apéndices zoomorfos, y esferoides líticos.

Los Remanses: sector de playa elevada del río Victoria en las proximidades de la boca de Los Toldos. Se encuentra en un islote bajo denominado Los Remanses, donde durante el relevamiento había una ranchada de pescadores. Redepositados en la superficie se hallaron 27 fragmentos cerámicos lisos, incisos y modelados (asas) y cinco materiales líticos. Se realizó un sondeo de $0,30 \mathrm{~m}$ de profundidad donde se recuperaron 191 tiestos de alfarería lisa, 18 rodados, 13 restos faunísticos (valvas de moluscos, mamíferos indet.) y materiales modernos (vidrio y metal).

Los Tres Cerros 1, 2, 3: conjunto de tres montículos adyacentes al arroyo de la Cruz, alineados en dirección NO-SE a lo largo de $239 \mathrm{~m}$. Al momento del relevamiento, los sitios Los Tres Cerros 1 y 2 estaban alterados como producto de la concentración del ganado durante la inundación del año 2007. El sitio 1 se localiza entre los sitios 2 y 3. El mismo presenta construcciones modernas, para cuya edificación se sobreelevó artificialmente el montículo. En su superficie se recuperaron 53 fragmentos cerámicos lisos, incisos y modelados (apéndices y "campanas") y posibles restos de arcilla cocida. 
En el sitio 2, ubicado a $133 \mathrm{~m}$ del sitio 1, se registraron 61 fragmentos de alfarería lisa, incisa y modelada (asas, "campana") y un material lítico. El sitio 3, se encuentra a 106 $\mathrm{m}$ del $1 \mathrm{y}$ ha sido parcialmente erosionado por el arroyo. Se hallaron 14 fragmentos de cerámica lisa en la superficie del terreno.

Cerro Justo Norte: montículo en el interior de la isla de Otegui, sobre un albardón cercano al arroyo Barrancoso. Se recuperó solo un tiesto liso en posición superficial, mientras que en un sondeo de $0,80 \mathrm{~m}$ de profundidad, se hallaron 29 tiestos lisos, cinco materiales líticos y restos de carbón, vidrio, metal y tejas.

Cerro Lote 11: montículo bajo, adyacente al arroyo San Lorenzo. Se encontraba alterado por el emplazamiento de una ranchada de nutrieros encima del sitio. En la superficie del terreno, afectado por el pisoteo del ganado, se registraron 70 fragmentos de cerámica lisa, incisa y modelada (asas), dos materiales líticos y objetos modernos. A partir de dos sondeos estratigráficos (sondeos 1 y 2 de 0,40 y $0,75 \mathrm{~m}$ de profundidad) se recuperaron materiales modernos (sobre todo en la parte superior del perfil) y prehispánicos (a lo largo de toda la secuencia). En estos sondeos se hallaron 265 fragmentos cerámicos lisos, incisos y modelados, cinco materiales líticos y 42 restos faunísticos (coipo, fauna introducida), junto a vidrio, carbón y metal. Del sondeo 2 se obtuvo una muestra de materia orgánica del nivel 0,65-0,70 m que fue datada en $490 \pm 60$ años AP (LP-1935).

La Tucura: montículo bajo en la intersección del río Victoria y un curso de la laguna La Viuda. Se encuentra muy modificado por un terraplén levantado para establecer una construcción moderna. Dispersos en la zona de playa contigua al montículo se registraron 74 restos cerámicos lisos y modelados (asas). Según información proporcionada por pobladores en el pasado se hallaron dos esqueletos humanos en este sitio.

Cerro de las Pajas Blancas: albardón con vegetación arbórea de 179 m de largo, rodeado por un bajo con pajonales. En la superficie del terreno y semi-enterrados han sido recuperados 36 fragmentos de cerámica lisa e incisa y cuatro restos de coipo. En un sondeo de $1 \mathrm{~m}$ de profundidad se recuperaron 575 fragmentos cerámicos lisos, incisos, pintados (rojo, blanco y negro), corrugados y masas de arcilla, dos rodados pequeños, 68 restos faunísticos de coipo, peces y moluscos de agua dulce, espículas de carbón, así como algunos elementos modernos en los niveles superiores (vidrio y metal). De una muestra de carbón obtenida a $0,27 \mathrm{~m}$ de profundidad se obtuvo una edad radiocarbónica de $650 \pm 70$ años AP (LP- 1925). De este sitio han sido recuperadas vasijas enteras que fueron dadas a conocer por Badano $(1940,1957)$, entre las que se destaca una urna funeraria decorada con pintura roja sobre fondo blanco y unguiculado.

\section{Distribución espacial, procesos de formación y tecnología}

La acción del agua, del ganado y de las poblaciones humanas actuales, por un lado, altera los depósitos arqueológicos y, por otro, favorece el acceso a los sitios y la detección de materiales arqueológicos en la superficie del terreno. La erosión hídrica forma barrancas que cortan los sectores elevados y ocasiona el transporte, fragmentación, rodamiento y redepósito de los materiales sobre las playas de cursos y cuerpos de agua. El ganado vacuno tiende a concentrarse en estas zonas altas, ya sea en busca de la sombra 
que brinda la vegetación arbórea o de superficies secas en momentos de ascenso del nivel del río, disminuyendo la altura de los montículos por el pisoteo continuo. Este agente, junto con las construcciones antrópicas modernas (puestos, corrales) y campamentos (ranchadas de pescadores o nutrieros), generan la remoción de sedimentos, áreas despejadas de vegetación herbácea y la fractura de los materiales. A esto se le suma la práctica de provocar incendios para renovar las pasturas.

Si bien las prospecciones han sido desarrolladas con mayor intensidad en el sector de islas respecto al de la llanura interior del sur entrerriano, los primeros resultados indican una mayor densidad de sitios en el primero de los sectores. En la zona de islas los sitios arqueológicos son muy abundantes y se ubican en contextos topográficos variados (Figura 2). Se localizan sobre playas, albardones paralelos a ríos, arroyos y lagunas, como en "cerritos" en el interior de las islas y frecuentemente en la intersección de dos o más cursos o paleocauces fluviales. También se detectaron conjuntos de "cerritos" con dos y tres montículos espacialmente asociados. Por su parte, la recurrente presencia de puestos y ranchadas sobre los sitios relevados, señala que estos montículos, muchos de los cuales han sido sobreelevados artificialmente por los pobladores actuales, siguen siendo estratégicos para la ocupación de este ambiente fluvial.

Los análisis de los materiales recuperados en las prospecciones (salvo la realizada en diciembre del año 2007), mediante sondeos y recolecciones superficiales, muestran que predomina ampliamente la cerámica en la gran mayoría de los sitios, mientras que los materiales líticos poseen bajas frecuencias (Figura 3). En la mayoría de los conjuntos los restos faunísticos también son escasos, a excepción de Cerro La Matanza 2 donde se halló el $92 \%$ de los restos registrados en todos los sitios.

En los sitios en los que se hallaron materiales óseos, a partir de las determinaciones taxonómicas efectuadas por el Lic. C. Leon (FCNyM; UNLP) se identificaron restos óseos humanos y de fauna autóctona. Aunque el análisis zooarqueológico está aún en proceso, los resultados preliminares indican la presencia de Myocastor coypus, peces (Siluriformes), Hydrochaeris hidrochaerus, Blastocerus dichotomus, Lontra sp., félidos, dasipódidos, así como exoesqueletos de Diplodon sp. y Ampullariidae. El coipo es la especie más representada y está presente en todos los conjuntos en los que se hallaron materiales faunísticos.

La Lic. V. Di Prado y L. Turnes (FCNyM) analizaron los atributos macroscópicos de 937 fragmentos de alfarería procedentes de los sitios Co. de Arena, La Horqueta, Co. El Durazno, Co. Barrancas y Los Laureles. Fueron halladas asas, bases, fragmentos de formas tubulares, cerámica incisa, pintada, corrugada, unguiculada, un solo apéndice zoomorfo y masas de arcilla. En relación a las superficies interna y externa, la mayoría de los tiestos presenta algún tipo de tratamiento en ambas superficies, predominando el alisado $(41,4 \%)$ y el pulido $(23,3 \%)$ sobre el engobado $(5,6 \%)$ y el corrugado $(1,9 \%)$. Con respecto a los tiestos en los que pudo identificarse la técnica de elaboración, predomina el rodete $(75,2 \%)$ y en menor medida el modelado (41\%). Los estudios petrográficos que están siendo realizados muestran distintos tipos de pastas con arenas finas a gruesas y 
tiestos molidos utilizados como antiplásticos. En relación a la atmósfera de cocción la más abundante es la oxidante incompleta $(69 \%)$, seguida por reductora completa $(27,2 \%)$. Al contrario de lo que sucede en las colecciones relevadas, predomina ampliamente la cerámica lisa (más del 90\%), aunque en todos los sitios analizados también se observan piezas decoradas mediante pintura roja, negra y/o incisiones.

Figura 2: Distintos contextos topográficos de los sitios del Delta Superior del Paraná. A: sitio sobre playa (Co. de Arena); B: sitio sobre albardón (Los Laureles); C: cerritos aislados (Co. El Duranzo) y D: conjunto de cerritos (Cerro de las Cañas 1 y 2)
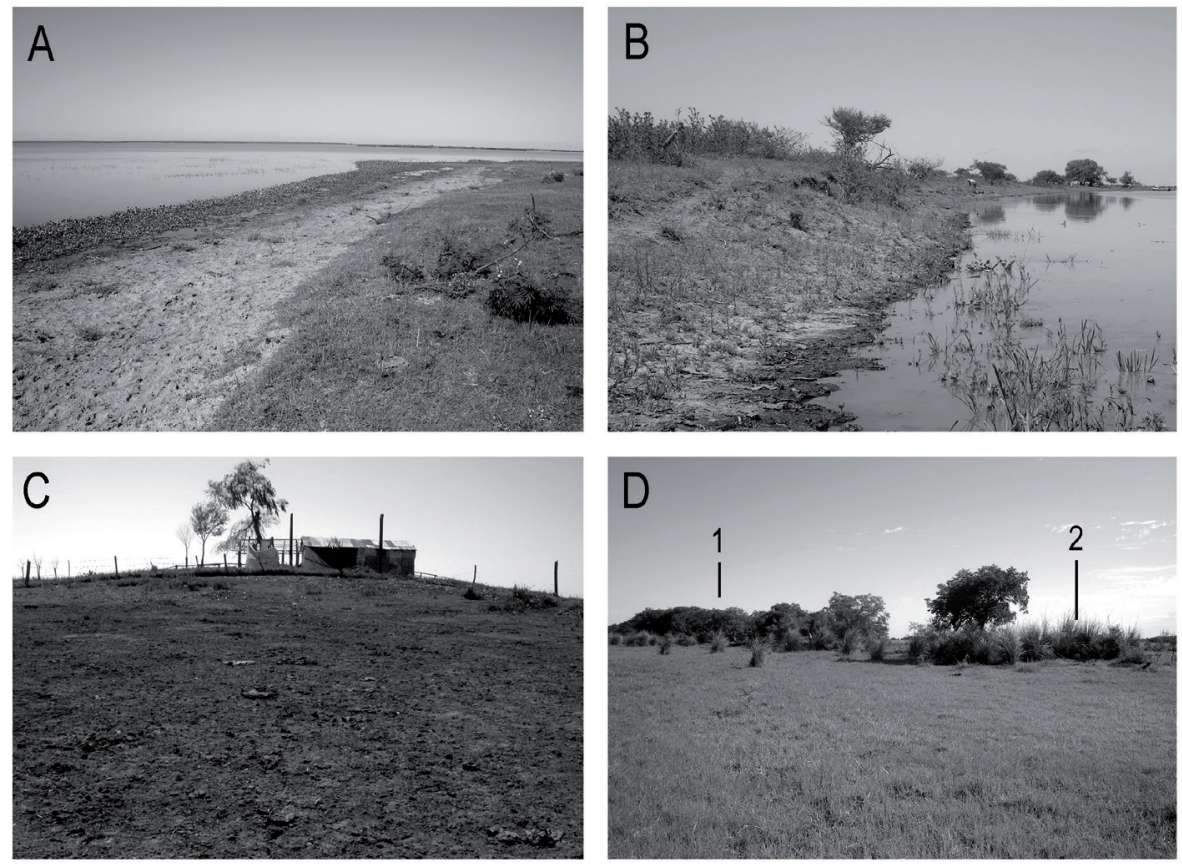

Entre los artefactos líticos, mediante análisis petrográficos, se reconocieron arenitas cuarzosas de la Fm. Ituzaingó (roca predominante en los conjuntos), rocas carbonáticas de la Fm. Paraná y calizas bioclásticas silicificadas semejantes a las Calizas del Queguay de Uruguay y Entre Ríos. Además, se identificaron a nivel macroscópico xilópalo, sílice y cuarzo-feldespato. Los instrumentos líticos manufacturados mediante lascados son escasos. Sólo se recuperaron dos denticulados, un raspador con filo frontal, un cuchillo con filo lateral y un esbozo de pieza bifacial. Los restantes 22 instrumentos fueron modificados por uso o elaborados mediante picado y/o abrasión. El análisis tecnomorfológico realizado por la Lic A. Matarrese (FCNyM) permitió identificar cuatro percutores, cuatro fragmentos de bordes de artefactos pasivos indefinidos, dos artefactos activos indefinidos, un artefacto pasivo de molienda sin evidencias de manufactura y un 
esferoide piriforme con surco en el eje mayor de la pieza que podría haber funcionado como bola de boleadora o peso para red. Este conjunto se completa con ocho piezas indeterminadas, algunas de las cuales presentan negativos de lascados como parte de una posible regularización de los planos de fractura. Estos análisis permitieron identificar un uso intensivo de los materiales de molienda, tal como se refleja por la abundancia de instrumentos reciclados.

Figura 3: Materiales recuperados en los sitios arqueológicos del Delta Superior del Paraná con más de 30 restos $(n=5259)$

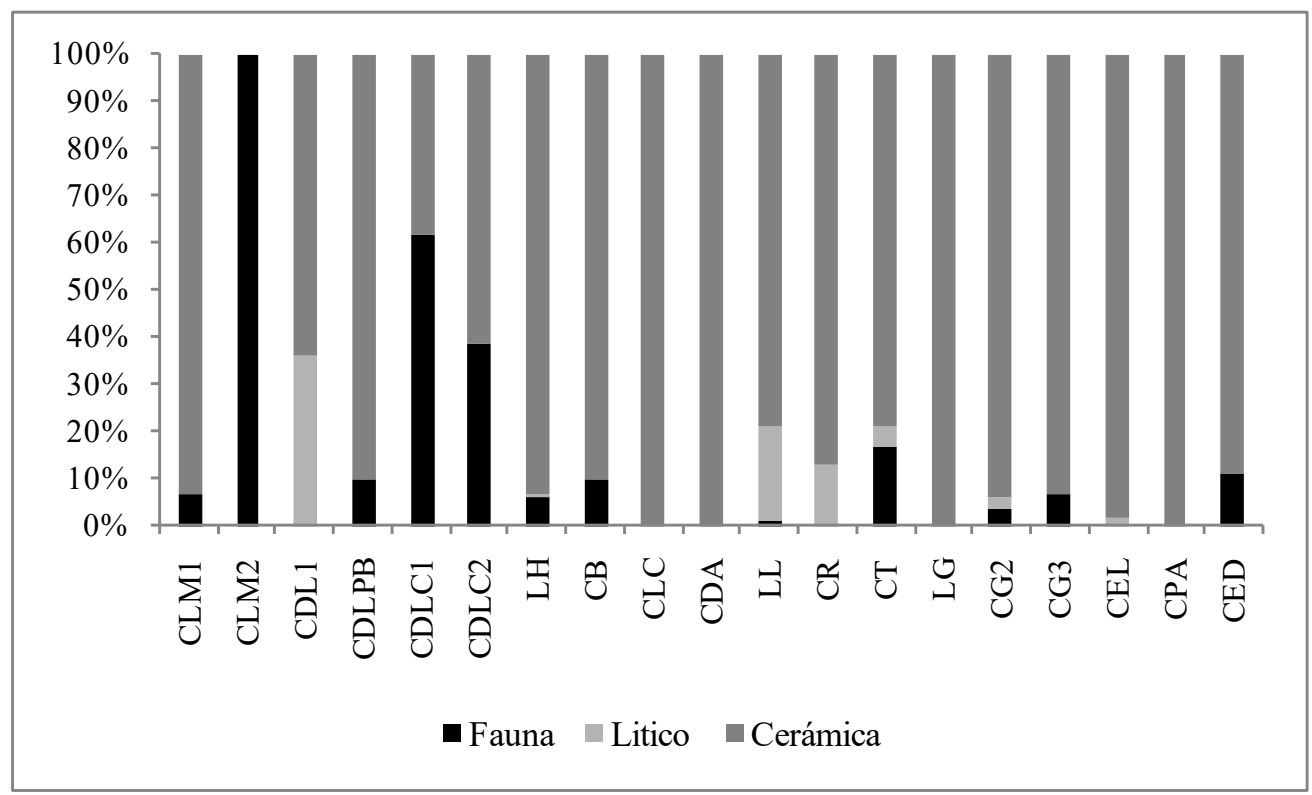

Asimismo, se han realizado, conjuntamente con la Dra. Pochettino (FCNyM) y el Dr. Aceituno (Universidad de Antioquia, Colombia) estudios de almidones sobre tiestos cerámicos y un instrumento pasivo de molienda. Las muestras provienen del Cerro Los Cardos y de la colección Torres del Museo de La Plata, específicamente del Túmulo I del Brazo Largo y del Río Paraná Miní. A partir de estos análisis se determinó la presencia de tejido epidérmico de algarrobo (Prosopis sp.) adherido a la pared interna de un tiesto cerámico. En las tres muestras también se identificaron numerosos almidones que corresponderían a porotos (Phaseolus vulgaris) y maíz (Zea mays). Estos resultados de los contenidos de almidón señalarían la manipulación intensiva de vegetales tanto silvestres como cultivados (Bonomo et al. 2007, 2008; Pochetttino et al. 2008). Actualmente se están llevando a cabo más análisis con el objeto de confirmar y precisar las determinaciones taxonómicas de las especies vegetales mencionadas. Si bien el consumo de especies cultivadas ya había sido planteado, sobre todo en base a datos históricos (por ejemplo de Aparicio 1939), esta sería una de las primeras evidencias arqueológicas que apoyan esto. 
Para empezar a discutir el patrón de ocupación humana del ambiente deltaico del área de estudio durante el Holoceno tardío y su relación con las variaciones geomorfológicas de los espacios disponibles para ser habitados, se analiza la distribución espacial de los sitios relevados en relación a la propuesta de Cavallotto y colaboradores (2005). De acuerdo a la localización topográfica de los sitios en las distintas unidades geomorfológicas definidas se observan las siguientes tendencias (Figura 4; Tabla 5):

- Se registran sitios arqueológicos en todas las unidades geomorfológicas identificadas en el área.

- E1 75\% de los sitios registrados ( $\mathrm{n}=39)$ se ubican en lugares elevados, los cuales no solo se encuentran en las distintas unidades geomorfológicas del sector de islas sujeto a inundaciones sino también en las llanuras altas.

- El 28,2\% de los sitios localizados en lugares elevados ( $\mathrm{n}=11)$ están constituidos por montículos en los que se aprovecharon las elevaciones de los albardones preexistentes, mientras que en los restantes montículos $(51 \%$ de los sitios elevados; $n=20)$ no se pudo establecer si se valieron estas elevaciones naturales previas.

- El 25\% de los sitios se localiza en lugares bajos ( $\mathrm{n}=13)$, tanto en playas como en médanos, sobre todo en las zonas de playa $(\mathrm{n}=10)$ como consecuencia de los procesos postdepositacionales que actuaron redepositando los conjuntos.

Tabla 5: Localización topográfica de los sitios arqueológicos detectados en relación a las unidades geomorfológicas propuestas por Cavallotto et al. (2005)

\begin{tabular}{|c|c|c|c|c|c|c|c|}
\hline $\begin{array}{c}\text { Unidades } \\
\text { Topografía }\end{array}$ & $\begin{array}{c}\text { Ilanura } \\
\text { alta }\end{array}$ & $\begin{array}{c}\text { Llanura } \\
\text { de mareas }\end{array}$ & $\begin{array}{c}\text { Ilanura de } \\
\text { cordones litorales- } \\
\text { médanos }\end{array}$ & $\begin{array}{c}\text { Ilanura de } \\
\text { playas }\end{array}$ & $\begin{array}{c}\text { Ilanura pre- } \\
\text { deltaica de } \\
\text { mareas }\end{array}$ & $\begin{array}{c}\text { depósitos } \\
\text { aluviales } \\
\text { internos }\end{array}$ & total \\
\hline albardón & 1 & 0 & 0 & 0 & 0 & 6 & 7 \\
\hline montículo & 0 & 1 & 0 & 4 & 11 & 4 & 20 \\
\hline $\begin{array}{c}\text { montículo } \\
\text { sobre albardón }\end{array}$ & 0 & 0 & 0 & 0 & 3 & 8 & 11 \\
\hline playa & 0 & 0 & 0 & 3 & 1 & 6 & 10 \\
\hline médanos & 0 & 0 & 2 & 0 & 0 & 0 & 2 \\
\hline otros & 2 & 0 & 0 & 0 & 0 & 0 & 2 \\
\hline total & 3 & 1 & 2 & 7 & 15 & 24 & 52 \\
\hline
\end{tabular}

Si tenemos en cuenta las dataciones obtenidas por Cavallotto et al. (2005) y las que están disponibles para los sitos arqueológicos del área, se observa que para el momento de ocupación de humana del Delta Superior del río Paraná (última parte del Holoceno tardío), todas las unidades geomofológicas ya se habían formado y por lo tanto 
estaban disponibles. Esto ocurre una vez que se estabiliza el paisaje deltaico y el nivel del mar, cuando desaparecen los factores ambientales que limitaron el establecimiento humano. Sin embargo, no todas tienen los mismos tipos de sitio. Aunque estos primeros resultados son aún preliminares, se observa como tendencia que la mayoría $(\mathrm{n}=11)$ de los sitios sobre montículo se encuentran en la llanura pre-deltaica de mareas, mientras que los que se asocian con albardones, montículos sobre albardones o playas están en los depósitos aluviales internos. En estos depósitos aluviales es también donde se registra la mayor cantidad $(\mathrm{n}=24)$ y densidad de sitios. Esta última observación apoya la idea de que las islas del Delta Superior fueron, en términos relativos, densamente ocupadas si de las compara con los otros sectores del río.

Figura 4: Mapa geomorfológico modificado de Cavallotto et al. (2005: Fig. 2) y ubicación de los sitios arqueológicos relevados

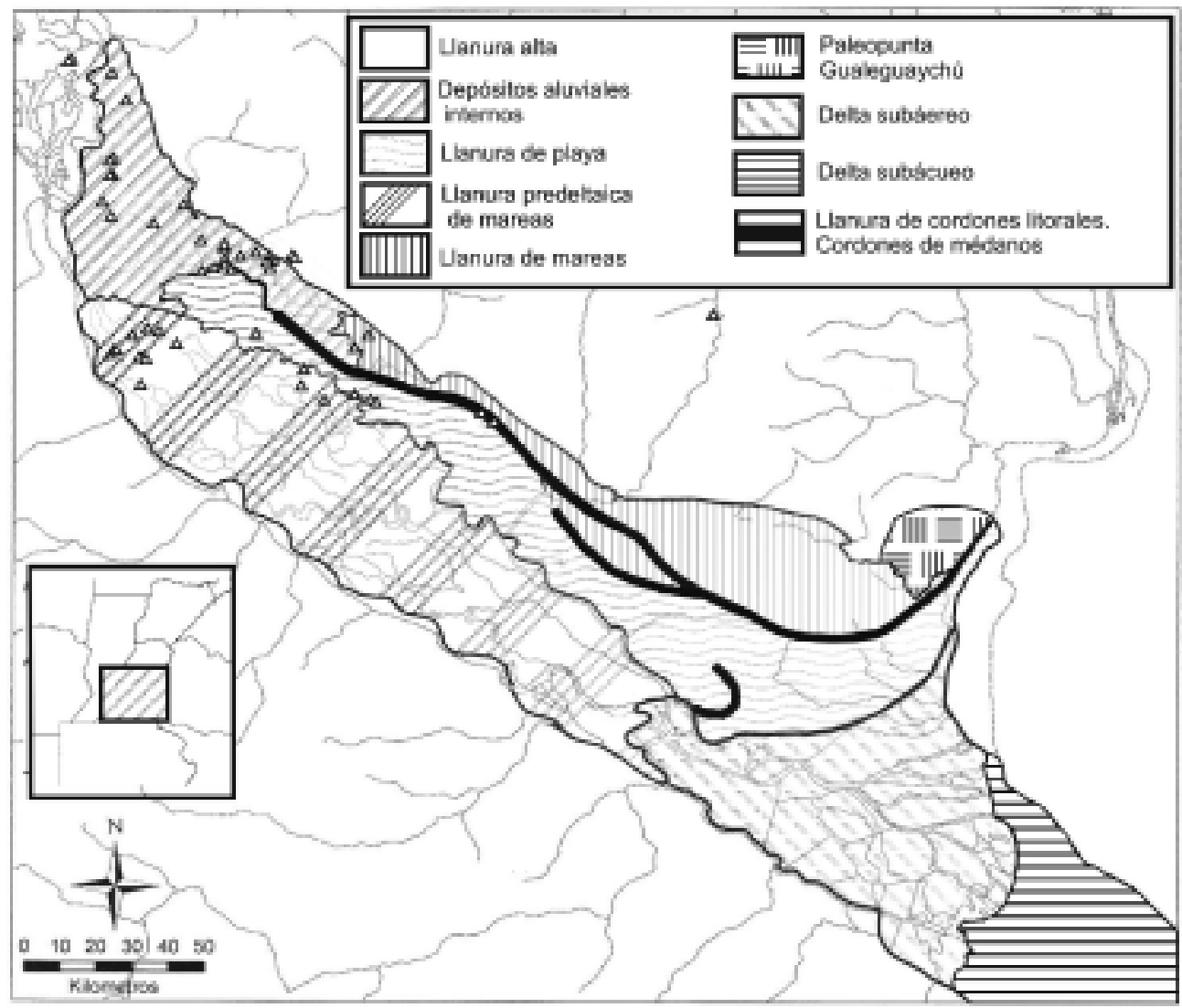




\section{Epílogo}

Las principales tendencias observadas a partir de las investigaciones arqueológicas desarrolladas en el Delta Superior del Paraná fueron las siguientes:

1- La mayoría de los sitios son campamentos residenciales que fueron ocupados en uno o varios momentos durante el Holoceno tardío. Se ubican preferentemente en el sector de islas (depósitos aluviales internos), sobre montículos y albardones. La importante cantidad de sitios registrados señala, en principio, una alta densidad (relativa) de ocupaciones en este ambiente fluvial.

2- La estrecha cercanía de los sitios con cursos y cuerpos de agua, así como su frecuente ubicación en la intersección de distintos cursos muestra que se privilegió la ocupación de lugares accesibles por vía acuática, donde las redes hídricas integraron los sistemas de circulación entre los sitios. Esto apoya el uso extendido de medios de navegación, de los cuales existen algunos hallazgos de canoas monóxilas de timbó para el Delta del Paraná y Río de La Plata (Brunazzo y Rivera 1997; Márquez Miranda 1932).

3- En los sitios relevados predomina la cerámica sin decoración y la presencia de masas de arcilla muestra la manufactura local de alfarería. Los artefactos líticos más abundantes son los elaborados sobre arenitas de la Fm. Ituzaingó mediante picado y/o abrasión o modificados por uso. En cuanto a la fauna Myocastor coypus es la especie dominante en los conjuntos y en principio, esto indica su importancia en la dieta de las poblaciones humanas del Delta Superior Es frecuente el entierro de esqueletos humanos en los mismos lugares de ocupación, tal como se registró en 13 sitios.

4- Los principales procesos postdepositacionales que alteran los sitios relevados y sus materiales arqueológicos son la acción del agua, del ganado y de las poblaciones humanas actuales. Estos procesos están actuando actualmente y en algunos casos han intensificado su acción en las últimas décadas. Entre otros agentes, esto podría ser el producto de la intensificación del uso de las islas para la cría de vacunos.

5.- En base a la escasa información radiocarbónica para el área de estudio, se plantea que una parte significativa de los sitios habrían sido formados o reocupados durante la última parte del Holoceno tardío (los últimos 1000 años). Sin embargo, aún no se han datado los niveles arqueológicos más profundos en ninguno de los sitios detectados y por lo tanto tenemos un conocimiento sesgado del patrón temporal de ocupación.

6.- Los estudios preliminares basados en las planimetrías y en observaciones geomorfológicas iniciales tienden a proponer que por lo menos una parte de los sitios en "cerritos" serían elevaciones intencionales del terreno. En el área de estudio se estarían dando los dos procesos antrópicos principales que formarían los "cerritos": uno sería el crecimiento gradual del cerrito como producto de la ocupación humana y el otro el aporte de sedimentos ad hoc para elevar artificialmente la superficie habitable. De confirmarse esta última hipótesis, también propuesta para el Delta Inferior del Paraná desde hace mucho tiempo atrás (p. ej. Torres 1911; Zevallos y Pico 1878), esta zona sería el límite meridional de una forma de arquitectura en tierra que tiene un amplio desarrollo en las tierras bajas de América del Sur (Bracco et al. 2000; Gianotti García 
2000; Iriarte et al. 2004; López Mazz 2001) y que presenta múltiples variantes que seguramente fueron la resultante material de procesos sociales y económicos diversos. En este sentido, los estudios que se están llevando a cabo contribuirán al creciente debate sobre la antigüedad, la función, el contexto social de formación y el crecimiento puntual vs. el gradual de los "cerritos" de las tierras bajas sudamericanas (véase Bracco et al. 2008 e Iriarte et al. 2008).

\section{Agradecimientos}

Este trabajo fue realizado con los recursos de los proyectos "Ocupaciones humanas prehispánicas en el Delta Superior del río Paraná (provincia de Entre Ríos)" (PICT 2006-0343), "Arqueología de los grupos cazadores-recolectores del sudeste del Área Interserrana Bonaerense" (UNLP, Código 11/N330) y "El paisaje cazador-recolector. Las formas del poblamiento en sociedades cazadoras-recolectoras atlánticas desde una perspectiva comparada" (CSIC-CONICET, n ${ }^{\circ}$ 2005AR0090). Además, este trabajo pudo ser realizado gracias a la colaboración de las siguientes instituciones: Parque Nacional PreDelta, CICYTTP-CONICET de Diamante, Municipalidad de Victoria, Prefectura Naval Argentina y Museo de Ciencias Naturales y Antropológicas "Prof. Antonio Serrano". Para finalizar, fue fundamental la ayuda brindada por Gisela Bahler, Juan Nóbile, Reynaldo Zanello, Pablo Giorgis, Alejandro Zucol, Ignacio Noriega, Ernesto Pressel, Juan Carlos Poledri, Fabián Daydé y Alejandro Sánchez y familia. Todos ellos hicieron posible nuestros trabajos de campo y colaboraron en muchos aspectos de esta investigación.

\section{Referencias Bibliográficas}

Aceñolaza, P., Manzano, A., Rodríguez, E. Sánchez, L., Ronche, A. L., Giménez, E., Demonte, D. y Marchetti, Z. 2008. Diversidad de la región superior del Complejo Deltaico del Río Paraná. En Temas de la Biodiversidad del Litoral III, Miscelánea 17. Editado por E. G. Aceñolaza, pp. 1-25. Tucumán: INSUGEO.

Ambrosetti, J. B. 1893. Sobre una colección de alfarerías minuanes recogidas en la provincia de Entre Ríos. Boletín del Instituto Geográfico Argentino 14: 242-265.

Badano, V. M. 1940. Piezas Enteras de Alfarería del Litoral Existentes en el Museo de Entre Ríos. Notas Arqueológicas II. Memorias del Museo de Entre Ríos 14. Paraná.

Badano, V. M. $1957 \quad$ El arte plástico de los ribereños paranaenses. Memorias del Museo de Entre Ríos 34:7-178.

Bonomo, M.; Politis, G.; Gianotti, C.; Cacheda, M. 2007. Patrones de Distribución Espacial de Sitios Arqueológicos en el Delta de Paraná de la Provincia de Entra Ríos. XVI Congreso Nacional de Arqueología Argentina. San Salvador. Jujuy. Argentina.

Bonomo, M.; Politis y G.; Gianotti. 2008. Tendencias temporales y espaciales de las ocupaciones humanas en el delta superior del Río Paraná. Trabajo presentado en el $V$ Congreso de Arqueología de la Región Pampeana Argentina. UNLPam. Santa Rosa.

Berón, M. A. y R. P. Curtoni. 2002. Atlas Arqueológico de la Provincia de La Pampa. Serie Monográfica, Volumen 2. INCUAPA. UNCPBA. Buenos Aires. Argentina 
Bracco Boksar, R., L. Cabrera y J. Lopez Mazz. 2000. "La Prehistoria de las Tierras Bajas de la Cuenca de la Laguna Merín,” En Arqueología de las Tierras Bajas. Editado por A. Durán Coirolo y R. Bracco Boksar, pp. 13-38. Montevideo: Ministerio de Educación y Cultura, Comisión Nacional de Arqueología.

Bracco Boksar, R., L. del Puerto, H. Inda y F. García-Rodríguez. 2008. Un aporte crítico a partir de "Comentarios sobre montículos de la cuenca de la Laguna Merín: tiempo, espacio y sociedad". Latin American Antiquity 19(3): 325-335.

Brunazzo, G. A. y S. M. Rivera. 1997. Rescatando Dos Canoas de las Aguas del Olvido. Un Aporte al Conocimiento de Embarcaciones Indígenas Recuperadas en el Partido de Berisso. Revista Museo 2(9): 87-91.

Caggiano, M. A. 1984. Prehistoria del noreste Argentino, sus vinculaciones con la República Oriental del Uruguay y sur de Brasil. Pesquisas, Antropología 38: 1-109.

Castro, J. C. 2007. Códigos para la identificación de sitios arqueológicos en la provincia de Entre

Ríos. Ficha Única de Localización y Registro de Yacimientos y Sitios Arqueológicos. Museo de Ciencias Naturales y Antropológicas "Prof. Antonio Serrano”. Paraná. Entre Ríos.

Cavallotto, J. L. 1995. Evolución geomorfológica de la llanura costera del margen sur del Río de La Plata. La Plata: Tesis doctoral inédita, Facultad de Ciencias Naturales y Museo.

Cavallotto, J. L.; Violante, R. A. y F. Colombo. 2005. Evolución y cambios ambientales de la llanura costera de la cabecera del río de La Plata. Revista de la Asociación Geológica Argentina 60 (2): 353 - 367.

Chiozza, Elena.1979. El país de los argentinos. Región metropolitana. El Delta. Centro Editor de América Latina., Buenos Aires

De Aparicio, F. 1939. El Paraná y sus tributarios. Historia de la Nación Argentina, R. Levene (ed.), pp. 419-442. Editorial Librería y El Ateneo, Buenos Aires.

De Feo, C.; Calandra, H.; Salceda, S.; Santini, M.; Aguirre, M. B.; Lamenza, G.; Lanciontti, M.; Del Papa, L. y A. Porterie. 2002. Localización Espacial y Caracterización Cultural de Sitios Arqueológicos del Gran Chaco Meridional. Actas del XXII Encuentro de Geohistoria Regional (Resistencia 2002). IIGHI - CONICET. Chaco. Argentina

Gaspary, F. 1950. Investigaciones Arqueológicas y Antropológicas en un Cerrito de la Isla Los Marinos (Pcia. de Entre Ríos). Publicación del Instituto de Arqueología, Lingüística y Folklore. Tomo XXIII. Córdoba.

Gianotti García, C. 2000. Monumentalidad, ceremonialismo y continuidad ritual. En C. Gianotti García (edidora); Paisajes Culturales Sudamericanos: De las Prácticas Sociales a las Representaciones. Tapa 19: 87-102. Santiago de Compostela, España.

Gonzalez, A. R. 1947. Investigaciones arqueológicas en las nacientes del Paraná Pavón. Córdoba: Universidad Nacional de Córdoba.

Iriarte, J., I. Holst, O. Marozzi, C. Listopad, E. Alonso, A. Rinderknecht, y J. Montaña. 2004. Evidence for cultivar adoption and emerging complexity during the mid-Holocene in the La Plata basin. Nature 432: 614-617.

Iriarte, J., I. Holst, O. Marozzi, C. Listopad, E. Alonso, A. Rinderknecht, y J. Montaña 2008. Comentario sobre "Montículos de la cuenca de la Laguna Merín: tiempo espacio y sociedad". Latin American Antiquity 19 (3) 317-324.

Iriondo, M. 1980. Esquema evolutivo del Delta del Paraná durante el Holoceno. Resúmenes del Simposio sobre problemas geológicos del litoral bonaerense: 73-88. Mar del Plata.

Iriondo, M. 2004. The littoral complex at the Paraná mouth. Quaternary International 114: 143154. 
López Mazz, J.M. 2001. Las estructuras tumulares (cerritos) del Litoral Atlántico uruguayo. Latin American Antiquity 12(3): 231-255.

Loponte D., A. Acosta y J. Musali. 2004. Hacia la complejidad social: cazadores-recolectores y horticultores en el sector centro-oriental de la Región Pampeana, En Aproximaciones contemporáneas a la arqueología pampeana. Editado por G. Martínez, G., M. Gutiérrez, R. Curtoni, M. Berón y P. Madrid, pp. 41-60. Olavaría: Facultad de Ciencias Sociales.

Lothrop, S. 1932. Indians of the Paraná Delta, Argentina. Annals of the New York Academy of Science 32: 77-232.

Márquez Miranda, F. 1932. La navegación primitiva y las canoas monóxilas. Revista del Museo de La Plata 9: 57-87.

Nóbile, J. 2002. Asentamiento y Subsistencia en la llanura aluvial del río Paraná (Sector Bajo Paraná): Aproximaciones a un modelo regional, En Arqueología Uruguaya hacia el fin del milenio 1. pp. 187-193. Montevideo: Gráficos del Sur.

Pochetttino, M. L., N. Petrucci y P. Riat. 2008. Informe sobre microfotografías de almidones hallados en artefactos, Delta del Paraná. Facultad de Ciencias Naturales y Museo-UNLP. MS.

Poujade, R. A. 1995. Mapa Arqueológico de la Provincia de Misiones. Secretaria de Estado de Cultura de la Provincia y Entidad Binacional Yacyretá. Pp 35. Misiones. Argentina

Raviña, M. G. y A. B. Callegari. 1988. Mapa Arqueológico de la Provincia de La Rioja. Revista del Museo de La Plata (Nueva Serie). Sección Antropología, Tomo IX, pp. 21-91. La Plata. Buenos Aires

Rocchietti, A., N. De Grandis, B. Vicioso y M. Valentini. 2007 Economía islera en el Holoceno tardío: un modelo exploratorio para las distribuciones arqueológicas de la latitud MonjeGaboto. Resúmenes expandidos del Segundo Encuentro de discusión arqueológica del Nordeste argentino. Paraná.

Rowe, J. 1971. Howland Site Designations in the Americas. American Antiquity, 36. Pp 477-480. Washinton. E.E.U.U.

Tarragó, M. y P. Díaz. 1972. Sitios Arqueológicos del Valle Calchaquí. Estudios de Arqueología, $\mathrm{N}^{\mathrm{o}}$ 1. Museo Arqueológico de Cachi. Salta.

Tarragó, M. y P. Díaz. 1973. Sitios Arqueológicos del Valle Calchaquí (II). Estudios de Arqueología, $\mathrm{N}^{\mathrm{o}}$ 2. Museo Arqueológico de Cachi. Salta

Tarragó, M. y V. Nuñez Regueiro. 1972. Un Diseño de Investigación Arqueológica Sobre el Valle Calchaquí: Fase Exploratoria. Estudios de Arqueología, No 1. Museo Arqueológico de Cachi. Salta

Torres, L. M. 1911. Los primitivos habitantes del Delta del Paraná. Buenos Aires: Universidad Nacional de La Plata, Biblioteca Centenaria 4.

Zeballos, E. y P. Pico. 1878. Informe sobre el Túmulo Prehistórico de Campana. Anales de la Sociedad Cientifica Argentina 6: 244-260. 